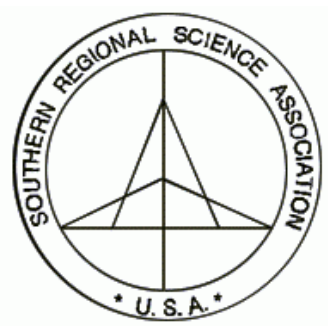

The Review of Regional Studies

Oklahoma State University

\title{
A Spatial Econometric Analysis of Regional Specialization Patterns across EU Regions
}

\author{
Claudia Stirboeck \\ Department of Economics, Deutsche Bundesbank \\ 60431 Frankfurt am Main, Germany, email: claudia.stirboeck@bundesbank.de
}

\begin{abstract}
In this paper, I perform a spatial econometric analysis of the determinants of regional specialization patterns across EU regions. Spatial correlation is evident, but this is due mostly to spatial error autocorrelation. Spatial interaction caused by positive economic interdependencies might be present for a very few labor-intensive sectors, yet it is inconsistent across different spatial weights matrices. No clear, disadvantageous spatial interdependencies of specialization in the periphery or increasing core-periphery tendencies were identified.
\end{abstract}

Keywords: Regional specialization; Exploratory spatial data analysis; Spatial econometrics

JEL classification: C31; F15; F2; R12

The opinions expressed in this paper represent those of the author and do not necessarily reflect the official position or policy of the Deutsche Bundesbank. The paper was written while the author was a research fellow at ZEW (Zentrum für europäische Wirtschaftsforschung) in Mannheim, Germany. Financial support by the Volkswagen Stiftung within the project No. II/76547 is gratefully acknowledged. I would like to thank Simone Giloth and Felix Morck for excellent research assistance and Dennis Quinn for being so kind as to let me use his liberalization indicators. I am indebted to Manfred M. Fischer, Jürgen Kaehler, Ronald L. Moomaw, participants at the ERSA 2003 conference, and two anonymous referees for helpful comments. All remaining errors, however, are my own. 


\section{RATIONALE}

Economic integration is supposed to foster specialization. However, there are various sides to specialization that might not be equally beneficial for all regions. Fears of increasing disadvantageous core-periphery tendencies have risen since Krugman's seminal 1991 study of potential agglomeration tendencies in EMU. Regional specialization and sectoral location patterns as well as the determinants of sectoral location have thus been at the forefront of regional economics over the past few years.

This study seeks to contribute to the debate through a spatial econometric analysis of the determinants and spatial interdependencies of regional specialization patterns in the European Union. First I examine the robustness of recent findings on the economic and locational determinants of regional specialization patterns, and second I study patterns of spatial interaction in regional specialization. This is important because some specific regional specialization might not be independent of that of the neighboring region. In contrast to recent studies, this investigation explicitly models and controls for spatial autocorrelation or interdependence by use of spatial econometric approaches and different spatial weights matrices. We find little evidence of significant economic spatial interdependencies that would lead to polarization or to declustering and no indication that integration was causing stronger regional specialization for specific sectors. But we generally detect spatial error autocorrelation that points to problems with regional definitions. And, importantly, we show that the OLS results on the determinants of regional specialization are robust.

Several mainly descriptive studies (Molle 1997; Walz 1999; Hallet 2002; Suedekum 2006, to name a few) investigate regional specialization; however, where they differ is with respect to the development of the level of specialization. Additionally, Stirboeck (2002a) does not find a clear trend of regional specialization levels over the 1985-1994 period, the same reporting period used here. However, the latter study detects an increasing impact of market integration on the level of regional dissimilarity, a result I expect to strengthen further. This might also influence sectoral specialization patterns, which are analyzed in the present study.

Amiti (1999), Haaland et al. (1999), Brülhart (1998), and Midelfart-Knarvik et al. (2000) go above and beyond the purely descriptive studies by focusing on explaining the concentration or location of sectors across space at the level of EU countries; Paluzie, Pons, and Tirado (2001) do the same across Spanish regions and Combes and Lafourcade (2001) across French regions. These studies confirm the significant role that market potential, human capital intensity, labor intensity, intermediate goods intensity as well as economies of scale and transportation costs play for the concentration or the location of (different kinds of) sectors. However, only Stirboeck (2002a, 2002b, 2004) and KalemliOzcan, Sorensen, and Yosha (2003) have attempted to explain the level and patterns of regional specialization, which are at the focus of this study. This article builds on recent research by Stirboeck (2004) that gives insights into the determinants of regional specialization patterns. According to traditional and new trade theories, a number of 
economic determinants summarized below matter in explaining regional specialization patterns.

The above-mentioned study identifies locational indicators (e.g., market size or potential and core-periphery location) as very important in explaining regional specialization patterns. First, market potential exerts a significant influence: specialization in manufacturing sectors is higher in those regions profiting from higher gross regional product (GRP) levels. Second, as Stirboeck (2004) demonstrates, peripheral regions - in contrast to core regions - play a different role in attracting sectoral employment and (especially) investment. The driving forces of sectoral specialization are favorable for core regions with respect to growth-oriented market services. The greatest regional specialization in services sectors in peripheral regions is instead linked to economic activity in tourism. In addition to some of the services sectors, relative investment and employment in non-market economic activities are stronger in peripheral regions.

Economic openness (representing market integration), however, does not play a particular or consistent role in explaining relative specialization in specific sectors according to Stirboeck (2004). Neither do fixed time effects, since average specialization does not steadily increase or decrease over time. This is also evident in the descriptive analyses of the regional specialization levels and regions' sectoral specialization presented by Stirboeck (2002a, 2004).

Country-specific effects, however, are evident, especially for employment specialization: in this respect Italy differs from the other countries in that it exhibits larger relative employment shares in a number of labor-intensive sectors and smaller shares in manufacturing sectors. In the context of our spatial econometric analysis, it is now especially important to investigate whether spatial interdependencies are behind the identified spatial differences since the existence of country-specific effects and, especially, locational impacts points to potential spatial interdependencies.

Consequently, one shortcoming of recent analyses is their disregard of spatial interaction. Theory tells us that regional specialization tendencies, cross-border spillovers and specialization clusters may be highly important and spatially interdependent. The existence of increasing returns in the face of transportation costs across space are at the bottom of agglomeration tendencies and limit the inter-regional division of labor and the decentralized production to supply local demand, a point stressed by Venables (2005) in a recent overview on spatial interactions in the world economy.

The explanation of economic agglomeration has been an element of economic theory for some time. According to the polarization theories, circular and cumulative agglomeration might occur in some regions on the basis of demand and supply linkages sometimes referred to as "forward and backward linkages" (Hirschman 1958; Myrdal 1957). The "New Economic Geography" (Krugman, 1991) explains the local concentration of scale-intensive production. It is expected to be localized close to large markets where supply and demand are concentrated to minimize transportation costs. The (partial) 
immobility of labor (Venables 1996; Krugman and Venables 1995), however, prevents complete agglomeration and predicts a U-shaped pattern of sectoral concentration.

Forces working in the direction of positive spatial interdependencies can be summarized as "efficiency gains" (see Venables 2005, p. 6). Specifically, these can result from knowledge spillovers, ${ }^{1}$ i.e., technological externalities, as well as intra-sectoral demand and supply linkages. In the case of inter-sectoral linkages, manufacturing as a whole might be clustered (see Venables 2005, p. 7). In general, we would expect such positive spatial lag dependencies, whereas the possibility of negative spatial interactions at the sector level is not straightforward economically. ${ }^{2}$ They might be the result of, first, a heavily scale-intensive production that makes the decentralization of production inefficient and second, high transport costs that theoretically work against the development of one single place of production of final goods. This eventually delivers certain optimal market areas such as Lösch's hexagon market areas or Thünen's rings or crop patterns (see Lösch 1940; Thünen 1875). If these developments are combined with intra-sectoral linkages, we might, in an extreme case, be confronted with a "de-clustering" of similar production areas and thus negative sectoral spatial interdependencies.

On the one hand, ignoring these regional interdependencies in the estimates of the determinants of regional specialization patterns might lead to inefficient inference due to spatial autocorrelation effects. In an extreme case, econometric results based on traditional estimates can be misleading. On the other, it is of interests to directly address the existence of spatial interactions, i.e., economic interdependencies, as well. Therefore, this paper will examine the robustness of recent findings on the economic and locational determinants of regional specialization patterns, controlling for spatial correlation. In addition, we will also investigate the existence and kind of spatial interdependencies or interaction driving economic developments or specialization tendencies.

\section{DATA AND INDICATORS}

We analyze EU regions at the NUTS 2 level for the 1985-1994 period. The definition of NUTS regions is based on political or administrative criteria, not on economic criteria. Analyzing NUTS regions might not therefore give us the actual degree of specialization of economic entities. However, data on economic or functional regions are not available from official databases. Defining relevant economic regions depends on the variable or sector in question, which implies that a general definition may not be appropriate. By analyzing administrative entities instead, we can focus on the degree of specialization of

\footnotetext{
${ }^{1}$ For a broad discussion of the facets of knowledge spillover, see Keilbach (2000).

${ }^{2}$ At the product level, it is easy to imagine that in a monopolistic market, one firm delivers within a certain market area encompassing several regions while the next firm is located some distance away.
} 
a territorial community that is authorized to implement regional policies or is the focus of regional structural programs. ${ }^{3}$

The maximum number of regions with sufficient sectoral investment and employment data is 56. Almost all of them are located in France (22), Italy (20), and Belgium (11). The three mono-regional countries Luxembourg, Denmark, and Ireland (which are also defined as NUTS 2 regions) are also included. Because the sum total of regional investments is not available for the 11 Belgian regions, these are excluded from the empirical analysis of investment specialization. Up to 17 distinct sectors - consistent with Eurostat's industrial classification NACE 1970 (Nomenclature des activités économiques dans les Communautés Européennes) - are contained in the REGIO database. They cover agriculture and manufactured products as well as market and non-market services.

In our analysis of the sectoral specialization patterns of the 56 regions, we focus on the regional investment and employment shares relative to a reference economy. We thus measure the specialization of gross fixed capital formation (GFCF) in relation to EU patterns (SP.GFCF.EU) as well as the specialization of employment in relation to EU patterns (SP.EMP.EU). This relative perspective is important as the absolute allocation of production across sectors does not give any information about a region's particularly high level of sectoral activity. ${ }^{4}$

In order to measure relative investment indices, we refer to adapted Balassa indices, ${ }^{5}$ which reflect a given region's relative investment performance and relative employment performance. Taking the calculation of investment specialization as an example, the capital formation $(I)$ share of the respective region $s_{i j}^{I}$ is set in relation to the average sectoral share of EU value added $r_{i}{ }^{6}$ :

\footnotetext{
${ }^{3}$ Regional policies have generally been applied in NUTS 2 regions since the 1961 Brussels Conference on Regional Economies (Eurostat 1999).

${ }^{4}$ While measures of absolute allocation are influenced by the sectoral classification, measures of relative allocation are influenced by the sectoral patterns of either the reference economy or the average pattern of the group of countries included. If the reference economy shows a very specific pattern, the relative specialization pattern of the economic entities analyzed can be biased. See, e.g., Stirboeck (2001) or Krieger-Boden (1999).

${ }^{5}$ This kind of specialization index was first applied by Balassa to use export data to analyze the relative export "performance" of a country and is known as the "revealed comparative advantage" index in international trade theory (see, e.g., Balassa 1989, p. 19).

${ }^{6}$ As sectoral investment and employment data are not in all cases as complete as we wish it to be, we had to use different but equivalent data representing the economic extent or importance of the different sectors at the EU level to calculate sectoral specialization indices. We therefore use gross value added at factor costs as the denominator when calculating the specialization indices in relation to patterns of EU averages. This way, we apply the same denominator to both specialization patterns, thus increasing their comparability.
} 


$$
\text { SP.GFCF.EU } U_{i j}=\frac{s_{i j}^{I}}{r_{i}}=\left(I_{i j} / \sum_{i} I_{i j}\right) /\left(\sum_{j} x_{i j} / \sum_{i} \sum_{j} x_{i j}\right)
$$

with $i(j)$ as the sectoral (regional) index.

If the region's investment or employment in one sector is relatively high (low) compared to the average sectoral share of EU value added, the index is greater (less) than $1 .^{7}$

\section{SPATIAL ASSOCIATION PATTERNS: REGIONAL CLUSTERS OF INVESTMENT AND EMPLOYMENT SPECIALIZATION}

Geographic clusters of regions specialized in similar industries or sectors can be analyzed and described by a number of different spatial association statistics. In the following, we refer to the Moran I statistics as a measure of global spatial association (relative to the sector as a whole), as well as to the Getis-Ord statistics as a measure of local spatial association (comparing each region to the surrounding ones). The latter can be described as a decomposition of the global measure into the contributing factors of spatial association. Moran's I gives information on the spatial autocorrelation of an economic variable across the entire set of regions, i.e., its strength as well as its nature. Moran's I is positive (negative) if there is a significant clustering of similar (dissimilar) values. However, it does not differentiate between specific but different clusters and does not inform us about the clusters' locations. The Getis-Ord statistics provide us with further insights. First, they detect clusters of regions with similarly high and low values on the basis of a positive and negative Getis-Ord value, respectively. Second, they tell us which regions feature significant positive spatial correlation, thereby influencing the global measure of spatial association.

The choice of an inverse squared distance matrix to capture the structure of spatial interaction is determined by the assumption that the inter-regional influence on sectoral specialization should be decreasing with increasing distance. In order to build regional distance matrices, we use the coordinates of the administrative centers of the respective regions because we can assume them to be equivalent to economic centers in most cases.

The Moran I statistics in Table 1 show significant global spatial association for a number of sectors. Where this is the case, the spatial association turns out to be positive, i.e., regions similarly strong or weak in sectoral specialization are regionally clustered. Any negative Moran I value turns out to be insignificant. We thus find no evidence of

\footnotetext{
${ }^{7}$ In a very few cases (four, to be precise), negative investments were replaced with zero investments in order to avoid problems in the interpretation and calculation of further indicators. Such negative investments are mostly due to realignments and depreciation and are always close to zero investments.
} 
negative spatial autocorrelation induced by a significant systematic spatial allocation of dissimilar values. With respect to investment specialization, the significant positive spatial autocorrelation applies to 11 of the 17 sectors that are significant at least at the 10 percent level, but mostly at the 1 percent level: agriculture; fuel and power products; minerals and mineral products; metal products and machinery, etc.; food, beverages and tobacco; textiles and clothing; building and construction; recovery, repair, trade, lodging, and catering services; non-market services; and, finally, paper and printing products and various industries. The latter two, however, are only significant at the 10 percent level. Thus, regions with a high (low) specialization in one of the aforementioned sectors are more likely to be surrounded by regions with an equally high (low) specialization than by other regions. However, there are differences in the spatial association patterns for most sectors with respect to the regional specialization in investment and in employment. Sectors showing evidence of significant (positive) spatial autocorrelation for employment specialization, again mostly at the 1 percent level of significance, include: agriculture; chemicals industry; metal products and machinery; food industry, textiles and clothing; paper and printing industries; various industries; building and construction; recovery, repair, trade, lodging, and catering services; and other services.

\section{TABLE 1}

Moran I Statistics for Spatial Association

\begin{tabular}{llcc}
\hline & & GFCF & EMP \\
\hline Agricultural, forestry and fishery products & AGRO & $0.26^{* * *}$ & $0.50^{* * *}$ \\
\hline Manufactured products & & & \\
Fuel and power products & FUEL & $0.19^{* * *}$ & 0.00 \\
Ferrous and non-ferrous ores and metals, other than & META & -0.05 & 0.04 \\
$\quad$ & & & \\
$\quad$ radioactive & MINE & $0.32^{* * *}$ & 0.05 \\
Non-metallic minerals and mineral products & CHEM & $0.02^{* *}$ & $0.10^{* *}$ \\
Metal products, machinery, equipment, electrical goods & METP & $0.11^{* *}$ & $0.18^{* * *}$ \\
Transport equipment & TREQ & -0.03 & 0.04 \\
Food, beverages, tobacco & FOOD & $0.12^{* *}$ & $0.27^{* * *}$ \\
Textiles and clothing, leather and footwear & TEXT & $0.13^{* *}$ & $0.25^{* * *}$ \\
Paper and printing products & PAPE & $0.09^{*}$ & $0.28^{* * *}$ \\
Products of various industries & VARI & $0.10^{*}$ & $0.16^{* * *}$ \\
Building and construction & BUIL & $0.24^{* * *}$ & $0.26^{* * *}$ \\
\hline Services & & & \\
Recovery, repair, trade, lodging and catering services & TRLO & $0.23^{* * *}$ & $0.23^{* * *}$ \\
Transport and communication services & TRCO & 0.04 & -0.01 \\
Services of credit and insurance institutions & CRED & -0.02 & 0.03 \\
Other market services & OTHS & 0.03 & $0.40^{* * *}$ \\
Non-market services & NMSE & $0.24^{* * *}$ & 0.04 \\
\hline Significance level is based on calculation of 1,000 permutations. & & & \\
$* * * / * * *$ refers to a significance level of $1 / 5 / 10$ percent. & & & \\
\hline & & & \\
\hline & & &
\end{tabular}


Thus, the only sectors that similarly show significant positive spatial clustering for both factors of production are the following eight, all relatively labor-intensive sectors: agriculture; metal products and machinery; food industry; textiles and clothing; paper and printing products; various industries; building and construction; and recovery, repair, trade, lodging, and catering services. The descriptive statistics show that the regionally clustered over- (under-) proportional employment is also linked to over- or underproportional capital formation in these sectors - however, according to the Moran I statistics, we cannot tell whether the clusters of specialized regions are geographically identical for both employment and investment.

In contrast to the spatial allocation pattern of these eight sectors, we find the chemicals industry and other market services to be marked by spatial clustering of employment, though not investments. This means that capital formation takes place uniformly across space in these two sectors while employment is especially strong or weak (which is the case for other market services) in a number of neighboring regions. We also find that some of the capital-intensive sectors such as fuel and power products, minerals and mineral products as well as non-market services ${ }^{8}$ bring about regionally clustered over(under-) proportional capital formation, which goes along with a uniform regional allocation of employment in these sectors. Finally, in the 1985-1994 period analyzed, some of the most important European growth sectors like transport equipment, transport and communication services or credit and insurance services provide neither evidence of a regional clustering of high investments nor of high employment. Thus, investments and employment in these sectors seem to be allocated uniformly across space.

The spatial econometric analysis in Section 4 will provide further evidence on the kind of spatial dependence and the potential existence of economic spillovers in those sectors for which we found significant regional clustering of either one or of both, investments and employment. For now, we will focus on the identification of the geographic clusters of regions specialized in the same sector. The Getis-Ord statistics (presented in Tables 2 and 3) provide evidence of local spatial association, i.e., which regions are significantly surrounded by similarly specialized regions. ${ }^{9}$ Focusing on this measure, we can now specify which regions contribute to the global spatial association discussed above and whether the geographic clusters of specialized regions differ for investments and employment.

Employment specialization generally shows stronger local spatial association patterns than investment specialization, i.e., more regions are significantly surrounded by

\footnotetext{
${ }^{8}$ This broad sector can be assumed to be partly capital-intensive due to high-tech equipment, for example, used in business-consulting etc.

${ }^{9}$ The list of regions and their abbreviations can be found in the appendix in Table A1.
} 
similarly specialized regions. ${ }^{10}$ The only two exceptions are the fuel and power products as well as minerals and mineral products sectors, where investment specialization exhibits stronger spatial association. A strong similarity in geographic clusters of comparably specialized regions is evident for agriculture, metal products and machinery, food industry, textiles and clothing, various industries, paper and printing products as well as building and construction. This means that seven of the eight sectors simultaneously showing significant global spatial association according to the Moran I statistics for both employment and investment are also marked by relatively similar local spatial association patterns, i.e., regional clusters of, at the same time, over-proportional investments and employment. However, this is not the case for recovery, repair, trade, lodging, and catering services because the local spatial association patterns are different. ${ }^{11}$

For the other sectors that do not exhibit a strong or simultaneous global spatial association for both factors of production, the local spatial association patterns also differ, i.e., those regions marked by local spatial association are not the same for investment and for employment. We thus have evidence only of the similarity of local spatial association for investment as well as for employment for six manufacturing sectors and agriculture. This means that the spatial association patterns with respect to the two factors of production are mostly (i.e., in 10 out of 17 sectors) different. Overall, we can detect some clusters of sectoral specialization across EU regions, although they are not very striking. Southern Italian regions mostly show significant spatial association of high specialization in agriculture and building, but spatial association of low specialization for paper \& printing industries, metal products and machinery, as well as the food industries. Some regions of central Italy (Toscana, Emilia-Romagna, Marche) as well as Corse form a cluster of high specialization in mineral industries; other regions of central and northern Italy (Emilia-Romagna, Trentino-Alto Adige, Fruili-Venezia Giulia, Umbria, Liguria, Marche, Toscana, and Lazio) as well as Corse in textiles. Most Belgian regions show local spatial autocorrelation of low specialization in agricultural employment and of high specialization in credit and other services as well as non-market services and paper \& printing products. No other strong regional spatial autocorrelation patterns are visible.

\footnotetext{
${ }^{10}$ To some extent, this is also due to the fact that Belgian regions are excluded from the analysis of investment specialization. However, only eight sectors show significant regional spatial association of employment specialization for Belgian regions - with two sectors showing significant patterns for only two regions and one region, respectively.

${ }^{11}$ Three (six) Italian regions exhibit spatial autocorrelation of high (low) investment specialization while seven Italian regions and Corse show evidence of spatial autocorrelation of high employment specialization, in addition to 10 French regions and Ireland showing spatial autocorrelation of low employment specialization.
} 
TABLE 2

Local Spatial Association Patterns According to Getis-Ord Statistics:

Agriculture and Services Sectors

\begin{tabular}{|c|c|c|c|c|c|c|c|c|c|c|c|}
\hline \multicolumn{2}{|c|}{$\begin{array}{c}\text { Agriculture, } \\
\text { Forestry and } \\
\text { Fishery }\end{array}$} & \multicolumn{2}{|c|}{$\begin{array}{l}\text { Recovery, } \\
\text { Repair, trade, } \\
\text { Lodging, etc }\end{array}$} & \multicolumn{2}{|c|}{$\begin{array}{c}\text { Transport } \\
\text { and } \\
\text { Communication }\end{array}$} & \multicolumn{2}{|c|}{$\begin{array}{c}\text { Credit and } \\
\text { Insurance } \\
\text { Services }\end{array}$} & \multicolumn{2}{|c|}{$\begin{array}{c}\text { Other } \\
\text { Market } \\
\text { Services }\end{array}$} & \multicolumn{2}{|c|}{$\begin{array}{c}\text { Non-Market } \\
\text { Services }\end{array}$} \\
\hline$\overline{\text { GFCF }}$ & EMP & GFCF & EMP & GFCF & EMP & $\overline{\text { GFCH }}$ & EMP & GFCF & EMP & GFCF & EMP \\
\hline \multicolumn{12}{|c|}{ Spatial Association of High Values } \\
\hline PUG & PUG & VEN & LOM & CRS & LOM & LOR & LUB & & IRE & MPY & LUX \\
\hline CAL & SIC & ERO & CRS & $\mathrm{ABR}$ & CRS & CHA & ANT & & HAI & AQU & VBR \\
\hline CAM & CAL & LOM & PIE & LOM & PIE & ALS & BWA & & CHA & AUV & HAI \\
\hline $\mathrm{SIC}$ & BAS & & VEN & SAR & & & HAI & & DEN & RAL & NAM \\
\hline BAS & CAM & & SAR & & & & LOR & & ANT & POI & LIM \\
\hline MAR & MOL & & ERO & & & & DEN & & CTR & LIS & ANT \\
\hline LAZ & SAR & & UMB & & & & $\mathrm{CHA}$ & & PIC & PAC & \\
\hline & LAZ & & LIG & & & & OVL & & NAM & IRE & \\
\hline & & & & & & & VBR & & LIM & & \\
\hline & & & & & & & & & VBR & & \\
\hline & & & & & & & & & NPC & & \\
\hline & & & & & & & & & OVL & & \\
\hline & & & & & & & & & BWA & & \\
\hline & & & & & & & & & BRU & & \\
\hline & & & & & & & & & $\mathrm{HNO}$ & & \\
\hline & & & & & & & & & LRO & & \\
\hline & & & & & & & & & MPY & & \\
\hline \multicolumn{12}{|c|}{ Spatial Association of Low Values } \\
\hline PAC & WVL & MOL & AUV & & & & PUG & TOS & ERO & LAZ & LOM \\
\hline MPY & VBR & $\mathrm{SIC}$ & CHA & & & & CAL & LOR & VEN & VEN & FVG \\
\hline AUV & BRU & PUG & LIS & & & & SIC & LOM & UMB & ERO & $\mathrm{VAO}$ \\
\hline LRO & $\begin{array}{c}\text { BW } \\
\text { A }\end{array}$ & CAM & BRT & & & & & VEN & FVG & TOS & TAA \\
\hline CTR & LIE & BAS & $\mathrm{HNO}$ & & & & & & LAZ & FVG & LIG \\
\hline IRE & ALS & CAL & $\mathrm{BNO}$ & & & & & & CAL & CRS & \\
\hline PIC & LIM & & AQU & & & & & & BAS & TAA & \\
\hline DEN & NA & & POI & & & & & & CAM & ABR & \\
\hline & $\mathrm{M}$ & & & & & & & & & & \\
\hline \multirow[t]{8}{*}{ CHA } & OVL & & CTR & & & & & & MAR & UMB & \\
\hline & NPC & & IDF & & & & & & PUG & MAR & \\
\hline & ANT & & IRE & & & & & & SIC & & \\
\hline & PIC & & & & & & & & & & \\
\hline & IRE & & & & & & & & & & \\
\hline & HAI & & & & & & & & & & \\
\hline & CHA & & & & & & & & & & \\
\hline & DEN & & & & & & & & & & \\
\hline ecia & $\begin{array}{l}\text { are shc } \\
\text { oss fi: } \\
\text { tion it }\end{array}$ & aplo & $\begin{array}{l}\text { Indic } \\
\text { forma } \\
\text { nt. }\end{array}$ & 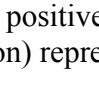 & $\begin{array}{l}\text { ial a } \\
\text { rela }\end{array}$ & & & $\%$ le & $\begin{array}{l}\text { of sig } \\
\text { ents ar }\end{array}$ & $\begin{array}{l}\text { cance. } \\
\text { EMP }\end{array}$ & \\
\hline
\end{tabular}


TABLE 3

Local Spatial Association Patterns According to Getis-Ord Statistics: Manufacturing Sectors

\begin{tabular}{|c|c|c|c|c|c|c|c|c|c|c|c|c|c|c|c|c|c|c|c|c|}
\hline \multicolumn{2}{|c|}{$\begin{array}{c}\text { Fuel and } \\
\text { Power } \\
\text { Products }\end{array}$} & \multicolumn{2}{|c|}{$\begin{array}{l}\text { Ores and } \\
\text { Metals }\end{array}$} & \multicolumn{2}{|c|}{$\begin{array}{c}\text { Minerals } \\
\text { and Mineral } \\
\text { Products }\end{array}$} & \multicolumn{2}{|c|}{$\begin{array}{l}\text { Chemical } \\
\text { Products }\end{array}$} & \multicolumn{2}{|c|}{$\begin{array}{l}\text { Metal products, } \\
\text { Machinery, } \\
\text { Equipment, etc }\end{array}$} & $\begin{array}{l}\text { Transport } \\
\text { Equipment }\end{array}$ & \multicolumn{2}{|c|}{$\begin{array}{c}\text { Food, } \\
\text { Beverages, } \\
\text { Tobacco }\end{array}$} & \multicolumn{2}{|c|}{$\begin{array}{l}\text { Textiles, } \\
\text { Clothing, } \\
\text { Leather, etc }\end{array}$} & \multicolumn{2}{|c|}{$\begin{array}{l}\text { Paper and } \\
\text { Printing } \\
\text { Products }\end{array}$} & \multicolumn{2}{|c|}{$\begin{array}{l}\text { Various } \\
\text { Industries }\end{array}$} & \multicolumn{2}{|c|}{$\begin{array}{c}\text { Building } \\
\text { and } \\
\text { Construction }\end{array}$} \\
\hline GFCF & EMP & GFCF & EMP & GFCF & EMP & GFCF & EMP & GFCF & EMP & GFCF EMP & GFCF & EMP & GFCF & EMP & GFCF & EMP & GFCF & EMP & GFCF & EMP \\
\hline \multicolumn{21}{|c|}{ Spatial Association of High Values } \\
\hline SIC & LIE & $\mathrm{HNO}$ & LUB & MAR & ERO & $\mathrm{BNO}$ & BRU & TAA & $\mathrm{BOU}$ & BOU $\mathrm{BOU}$ & IRE & IRE & ERO & ERO & POI & IRE & RAL & TAA & PUG & PUG \\
\hline CAL & ALS & IRE & ALS & TOS & MAR & IDF & IDF & LIG & VAO & CAM IRE & PDL & PDL & TAA & UMB & $\mathrm{BNO}$ & DEN & TAA & RAL & SIC & SIC \\
\hline CRS & & & LOR & ERO & TOS & NPC & DEN & VAO & IDF & VAO BNO & NPC & IDF & FVG & FVG & PIC & BRU & VEN & FVG & CAL & CAL \\
\hline PUG & & & $\mathrm{CHA}$ & CRS & CRS & PIC & PIC & BOU & TAA & $\mathrm{VAO}$ & IDF & BRT & LIG & TAA & IDF & CTR & & VEN & CAM & SAR \\
\hline BAS & & & DEN & LAZ & & & VBR & TOS & LIG & CTR & & BNO & UMB & MAR & IRE & PIC & & & SAR & CAM \\
\hline \multirow[t]{8}{*}{ CAM } & & & NAM & UMB & & & $\mathrm{BNO}$ & & AUV & & & $\mathrm{HNO}$ & MAR & TOS & AQU & NAM & & & BAS & BAS \\
\hline & & & & FVG & & & NAM & & & & & DEN & CRS & LAZ & & HAI & & & & \\
\hline & & & & TAA & & & IRE & & & & & LIS & & LIG & & VBR & & & & \\
\hline & & & & VEN & & & & & & & & & & CRS & & IDF & & & & \\
\hline & & & & & & & & & & & & & & & & ANT & & & & \\
\hline & & & & & & & & & & & & & & & & CHA & & & & \\
\hline & & & & & & & & & & & & & & & & $\mathrm{HNO}$ & & & & \\
\hline & & & & & & & & & & & & & & & & $\mathrm{BNO}$ & & & & \\
\hline \multicolumn{21}{|c|}{ Spatial Association of Low Values } \\
\hline \multirow{11}{*}{$\begin{array}{l}\text { HNO } \\
\text { CHA } \\
\text { RAL } \\
\text { IRE } \\
\text { DEN }\end{array}$} & & & & $\mathrm{BNO}$ & & & & $\mathrm{CAL}$ & CAM & & SIC & ERO & \multirow{11}{*}{\multicolumn{2}{|c|}{ MPY }} & PUG & CRS & \multirow{11}{*}{\multicolumn{2}{|c|}{ SAR }} & $\mathrm{HNO}$ & \\
\hline & & & & POI & & & & BAS & BAS & & CRS & MOL & & & SAR & CAM & & & CTR & BWA \\
\hline & & & & CTR & & & & PUG & CAL & & SAR & PIE & & & BAS & PUG & & & PIC & ANT \\
\hline & & & & IRE & & & & SAR & PUG & & & BAS & & & CAL & BAS & & & $\mathrm{CHA}$ & HAI \\
\hline & & & & & & & & SIC & SAR & & & LOM & & & SIC & SAR & & & IRE & IRE \\
\hline & & & & & & & & & SIC & & & UMB & & & & CAL & & & DEN & DEN \\
\hline & & & & & & & & & & & & PUG & & & & SIC & & & & \\
\hline & & & & & & & & & & & & CAL & & & & & & & & \\
\hline & & & & & & & & & & & & SAR & & & & & & & & \\
\hline & & & & & & & & & & & & SIC & & & & & & & & \\
\hline & & & & & & & & & & & & CRS & & & & & & & & \\
\hline
\end{tabular}


In addition, it is never the case that a significant regional cluster of over-proportional employment is linked to a regional cluster of under-proportional investment, and viceversa. Thus, investment (employment) in a sector is always also taking place in those regions specialized in sectoral employment (investment), albeit to an average extent; and we find no evident signs of changing specialization in the 1985-1994 period. The strength of regional specialization in either employment or investment for a sector, however, also seems to be determined by the sector's capital or labor intensity in some cases. For example, regional concentration of high investment in fuel and power products or minerals and mineral products is due to natural conditions that can only be exploited by the strong capital input, which again does not point to changing specialization patterns.

In summary, we find significant global spatial association in a number of sectors, in either investment or employment or both, and will analyze potential spatial interdependencies below. However, spatial association is not general, especially not across many manufacturing sectors where we would expect supply and demand linkages to foster agglomeration tendencies. Importantly, local spatial association patterns of a given sector are, in most cases (besides six manufacturing sectors and agriculture), not alike for both employment and investment. This might imply different locational reactions for laborintensive and capital-intensive production of one sector - which, however, cannot be investigated further with the sectoral aggregation at hand.

\section{SECTORAL SPECIALIZATION: COMPARING THE PATTERNS OF INVESTMENT AND EMPLOYMENT SPECIALIZATION}

\subsection{Theoretical Background: the Specification}

The extent of investment and employment specialization is explained - in separate estimates - by determinants of specialization patterns from traditional and new trade theories as well as regional economic theories (chiefly polarization theories). There are also recent comprehensive theoretical approaches such as Midelfart-Knarvik et al. (2001) that unite comparative advantage and geographical distribution of demand and eventually also motivate the analysis of the determinants discussed below.

In traditional trade theory, productivity and factor cost differentials between regions are important in explaining comparative advantages. Regions with abundant employment might specialize in labor-intensive sectors; regions relatively well-endowed with capital might focus on capital-intensive production. Thus, regional dissimilarities are based on unevenly distributed but exogenous factor allocations or technology differences. Polarization theory and the "New Economic Geography" alike attach great importance to the location of a region. Polarization theory is based on cumulative agglomeration tendencies in the center and predicts backwash effects for peripheral regions. The strong and detrimental specialization of peripheral regions combined with a beneficial specialization of central regions, might be a sign of backwash effects. A strong specialization of the central regions in the important growth-oriented sectors would support the hypothesis of the

polarization theory of potential cumulative agglomeration in the center. The New 
Economic Geography (NEG) emphasizes the importance of market size in explaining the location of sectors, i.e., it predicts that scale-intensive sectors concentrate production close to large markets. As long as sectoral location and regional specialization go hand in hand, determinants such as scale intensity and market size also might be important in explaining regional specialization. In addition, the NEG stresses that industries profiting from forward and backward linkages are likely to locate close to economic centers that are marked by strong demand or supply. Consistent with this, we assume that most important economic regions have disproportionately high employment or investment in those sectors. We expect the impact of market integration on the level of regional specialization to increase according to both traditional trade theory and the NEG. However, we do not know which sectors, if any, profit from market integration. Analyzing the role of economic openness for regional specialization might thus tell us which sectors, if any, are particularly influenced by increasing economic openness.

The specification we use to analyze spatial autocorrelation in the investment and employment specialization patterns is based on the specification introduced by Stirboeck (2004). However, we omit sectoral explanatory variables due to their restricted regional availability as well as R\&D intensity due to the short time period of available data. The location of a region in the economic center ${ }^{12}$ (CENTR) and the periphery (DIST) as well as the population density (PODEN) serve as locational explanatory variables that capture the impact of central location that is not simultaneously captured by CENTR. In addition, market potential proxied by gross regional product (GRP) is important in explaining specialization in scale-intensive sectors in the core regions. Economic openness, captured by an index constructed by Quinn (1997) on the basis of restrictions documented by the IMF (QUINN_OPENN), ${ }^{13}$ is the trigger of specialization in most trade theories. However, an analysis of it might reveal which regions are particularly affected by market integration. Finally, the regional geographic size (AREA) (controlling for the potentially higher diversification of larger regions) as well as the unemployment rate (UEWP) (approximating the regional economic performance, one key determinant of investment decisions) are added as further regional control variables. However, despite their significance in the analysis presented by Stirboeck (2004), the relevant regional labor costs and sector-specific productivity levels as comparative advantage variables as well as the economies of scale variable are not used in this analysis because they are not consistently available across the whole dataset.

\footnotetext{
${ }^{12}$ Approximatively, we refer to the administrative center to capture the impact of the economic center, which is a good procedure in the countries analyzed.

${ }^{13}$ This index varies from 0 to 14 in 0.5 steps. For further details on the evaluation of specific restrictions, see Quinn (1997). Although the index is only at the country level, the advantage of Quinn's index is its accuracy and thus its concreteness and its variation over time. Due to the high degree of integration already attained by EU countries, the yearly values for the observation points included in our analysis do not vary across the whole range of 0 to 14 , but lie between 10 and 14 . Since they vary in steps of 0.5 over time (e.g., between 10.5 and 14 for Italy and 11 and 13 for France over the 1985-1994 period), the inclusion of the openness index adds a dimension that differs clearly from pure country effects.
} 
We have thus included most of the important determinants that explain specialization patterns in Stirboeck (2004) and test the following specification for each sector in a pooled regression.

$$
\begin{aligned}
\text { SP.GFCF(EMP).EU } & =\beta_{0}+\beta_{1} \text { CENTR }_{j}+\beta_{2} \text { PODEN }_{j}+\beta_{3} \text { DIST }_{j}+\beta_{4} \text { GRP }_{j} \\
& +\beta_{5} \text { QUINN_OPENN }_{j}+\beta_{6} \text { AREA }_{j}+\beta_{7} \text { UEWP }_{j} \\
& + \text { country dummies }+\varepsilon_{i j}
\end{aligned}
$$

with $i(j)$ as the sectoral (regional) index. Since time-fixed effects are mostly insignificant, we pooled the available observations and omitted the time index in the above specification. However, we included indicator variables for the different countries (DUM_FRA, DUM_LUX, etc.) to capture country-specific impacts. Additional explanatory variables of interest to the question in focus would include indicators on regional climate, quality of soil, and the existence of a coastline because these strongly influence natural conditions. However, their inclusion would increase the number of indicator variables even further. Depending on the data availability for sectoral investments (employment), regressions are run for up to 45 (56) regions and up to 10 years (1985 to 1994).

Because we are dealing with regional data and analyzing the process of regional specialization, we cannot - as outlined above - exclude potential correlations or interactions between regional developments. Some specific regional specialization might not be independent of that of the neighboring region. Spatial econometric approaches ${ }^{14}$ explicitly model and control for spatial autocorrelation or interdependence to avoid inefficient or inconsistent parameter estimates or specification errors.

\subsection{Controlling for Spatial Correlation and Interaction in the Analysis of Investment Specialization Patterns}

In a first step, we refer to test diagnostics examining a potential spatial correlation structure in the residuals of classical, non-spatial OLS regressions by using the inverse squared distance matrix already discussed above. In order to test for robustness, the tests and estimates were additionally conducted by means of a neighborhood contiguity matrix that is one for the 10 nearest neighbors and thus assumes spatial interaction with 10 surrounding regions. ${ }^{15}$ In quite a number of cases, we cannot accept the null hypothesis of a significant normal distribution of the error terms. As a consequence, the test diagnostics on spatial autocorrelation should only be interpreted as an indicator of the potentially

\footnotetext{
${ }^{14}$ For detailed descriptions of spatial econometric tools, see e.g., Baltagi (2002), Anselin (1988), and Anselin andFlorax (2003).

${ }^{15}$ One common procedure is also to iterate or vary the spatial weights matrix in order to identify the matrix that gives the best fit for a particular specification. However, neither of the two spatial weights matrices used in this analysis provides evidence of its superiority across all sectors. We may therefore assume that there is not one optimal spatial weights matrix for all sectors.
} 
underlying structure of spatial correlation because they are not as reliable as in the case of normally distributed residuals.

The Moran I test investigates the existence of all kinds of spatial correlation, while the Lagrange Multiplier (LM) error and lag tests check for the significance of a specific kind of spatial structure. Table 4 presents the results of all three tests for the analysis of the determinants of sectoral investment specialization for each of the 17 sectors. We can see that in many cases a significant structure of spatial correlation exists. The significance is not consistent in the analysis of transport equipment and chemicals as well as transport and communication services and is only very weak for various industries. The sectoral specialization of the regions analyzed seems to underlie a positive spatial correlation in some sectors (AGRO, MINE, VARI, BUIL, TRLO, CRED, OTHS) and a negative one in other sectors (FUEL, META, METP, FOOD, TEXT, PAPE, NMSE) according to the inverse squared distance matrix. The correlation structure often has a different sign when referring to the alternative spatial weights matrix. ${ }^{16}$ In the case of spatial error correlation, the sign of the correlation structure is irrelevant for economic interpretation. And the fact that the sign varies indicates that we might not face economic spillovers (represented by spatial lag dependence) across space.

If we examine the specific kind of spatial correlation, we note that it is mixed as well (see Table 4). For most sectors, the LM tests for spatial structure are significant for both the spatial error model and the spatial lag model. Since both LM tests are sensitive to the alternative form of spatial structure, we refer to the higher value of the LM test in order to get an indication of the better specification according to Anselin (1992). ${ }^{17}$ For nine sectors, the LM tests provide evidence that the spatial error model is the better specification. Only two services sectors (credit and insurance services and other services) show positive spatial autocorrelation of the error terms, whereas it is negative for the other seven sectors.

For five sectors (agriculture; mineral products; various products; building and construction; and recovery, repair, trade, lodging and catering services) the tests show a higher value for the LM lag test. For all of these sectors, the tests consistently point to a positive spatial lag dependence. In economic terms, this would imply that the sectoral specialization of a region in one of these sectors positively influences the specialization of the neighboring regions in the same sector.

Table A4 in the appendix compares the results of the OLS estimates with those of the ML estimates of the spatial error and the spatial lag model for each sector. First, in those cases with higher LM error test values, the spatial error model is generally confirmed to

\footnotetext{
${ }^{16}$ Results are available from the author upon request.

17 The more specific "robust LM tests," which are robust against the alternative form of spatial structure, do not provide further evidence on the true structure of spatial correlation in our estimates. We do not include their results here, but instead refer to the standard tests.
} 
be the best model either according to the insignificant spatial lag parameter or to the lower AIC value.

Second, in those cases where LM lag test values are higher, the results of the ML estimates differ. Most notably, the AIC (and/or the likelihood ratio test value) indicates the superiority of the spatial error model formulation for agriculture as well as building and construction sectors, which show a positive spatial correlation structure. In addition, the positive spatial lag dependence is weak only for various products. But finally, as predicted by the OLS test diagnostics on spatial autocorrelation, the spatial lag model shows a positive spatial dependence for the sectoral specialization in minerals and mineral products as well as in recovery, trade, repair, lodging, and catering services. Referring to the spatial neighborhood contiguity matrix, however, the spatial lag dependence is only slightly superior for the fuel and power products sector.

Finally, again referring to the inverse squared distance matrix, the spatial parameters are insignificant - as we expected according to the OLS test diagnostics - in

\section{TABLE 4}

Regression Diagnostics for Spatial Autocorrelation of Investment Specialization (Inverse Squared Distance Matrix)

\begin{tabular}{lccc}
\hline & Moran I & $\begin{array}{c}\text { LM error } \\
\text { test }\end{array}$ & $\begin{array}{c}\text { LM lag } \\
\text { test }\end{array}$ \\
\hline Agricultural, forestry and fishery products & $4.3^{* * *}$ & $4.0^{* *}$ & $17.3^{* * *}$ \\
\hline Manufactured products & & & \\
Fuel and power products & $-8.2^{* * *}$ & $31.8^{* * *}$ & $5.8^{* *}$ \\
Ferrous and non-ferrous ores and metals, other than & $-14.2^{* * *}$ & $89.9^{* * *}$ & $48.0^{* * *}$ \\
$\quad$ radioactive & $10.3^{* * *}$ & $33.8^{* * *}$ & $53.9^{* * *}$ \\
Non-metallic minerals and mineral products & $1.7^{*}$ & $0.2^{* * *}$ & 0.7 \\
Chemical products & $-17.4^{* * *}$ & $133.3^{* * *}$ & $20.3^{* * *}$ \\
Metal products, machinery, equipment, electrical goods & $1.2^{* *}$ & 0.0 & 0.0 \\
Transport equipment & $-13.2^{* * *}$ & $80.2^{* * *}$ & $6.8^{* * *}$ \\
Food, beverages, tobacco & $-8.5^{* * *}$ & $35.3^{* * *}$ & $11.9^{* * *}$ \\
Textiles and clothing, leather and footwear & $-3.2^{* * *}$ & $7.1^{* * *}$ & 1.2 \\
Paper and printing products & $1.8^{*}$ & 0.2 & $6.3^{* *}$ \\
Products of various industries & $4.1^{* * *}$ & $3.6^{*}$ & $16.4^{* * *}$ \\
Building and construction & & & \\
Services & $10.1^{* * *}$ & $32.7^{* * *}$ & $62.4^{* * *}$ \\
Recovery, repair, trade, lodging and catering services & -1.2 & 2.0 & $6.4^{* *}$ \\
Transport and communication services & $6.4^{* * *}$ & $11.4^{* * *}$ & $6.7^{* * *}$ \\
Services of credit and insurance institutions & $10.5^{* * *}$ & $35.4^{* * *}$ & $12.9^{* * *}$ \\
Other market services & $-11.6^{* * *}$ & $57.0^{* * *}$ & $6.3^{* *}$ \\
Non-market services & & & \\
\hline
\end{tabular}


the estimates for chemicals (the spatial lag parameter is only significant at the 10 percent level while the specification is not confirmed by the LM lag test) and for transport equipment. The spatial error model is highly significant for the transport and communication services sector, for which the classical estimates residuals provide an insignificant Moran I value even though numerous coefficients included in the specification are no longer significant. Since this is the only case with evident changes in the significance of the explanatory variables, this points instead to a misspecification of the spatial error model for transport and communication services.

To summarize, the spatial autocorrelation is insignificant in the estimates for chemical products and for transport equipment and not convincing for transport and communication services. For most other sectors, the regional specialization exhibits spatial error autocorrelation that is negative in five cases but positive in the other five cases, albeit dependent on the spatial weights matrix used. We might be confronted with a spatial lag dependence; however, this is inconsistent across spatial weights matrices in the regional specialization in these sectors: recovery, repair, trade, and lodging; various products; minerals and mineral products; and fuel and power products. Apart from these four sectors, we definitely find no spatial interdependence between the sectoral specialization of neighboring regions. The underlying spatial error autocorrelation points instead to potential data problems or to inadequate regional classifications, a fact underlined by the weights matrix-induced change in the sign of the spatial autocorrelation structure when analyzing many sectors.

Finally, if we check the sensitivity of the results of traditional OLS estimates, we find no general problem of significance concerning the non-spatial parameters. The explanatory variables that are significant in the OLS estimates are usually also significant in the spatial estimates without changing their signs. Thus, the specialization patterns discussed in Stirboeck (2004) are robust even when controlling for spatial autocorrelation effects.

\subsection{Controlling for Spatial Correlation and Interaction in the Analysis of Employment Specialization Patterns}

The test diagnostics on spatial autocorrelation provide evidence of a spatial autocorrelation in the OLS estimates of employment specialization for most of the sectors. As for the estimates on investment specialization, the Moran I test is mostly significant - except for building and construction and other services. Again, the significance of the spatial autocorrelation structure is very strong across all those sectors. According to the inverse squared distance matrix, we now only find five sectors (AGRO, TEXT, PAPE, VARI, and NMSE) with a significant positive spatial autocorrelation while 10 sectors (FUEL, META, MINE, CHEM, METP, TREQ, FOOD, TRLO, TRCO, and CRED) show a significant negative spatial autocorrelation structure. However, if we use the neighborhood distance contiguity matrix, the spatial autocorrelation structure given by the Moran I test is always significantly positive. As is the case for investment specialization, the inconsistency of the test statistics' sign does not convincingly prove spatial dependence in regions' sectoral specialization. 
Referring to the LM tests to gain insights into the specific form of spatial autocorrelation that is present when using the inverse squared distance matrix, the LM lag test value is again mostly lower than the LM error test value. It is only higher with respect to agriculture, paper and printing products, various industries, and non-market services. It is also highly significant for building and construction as well as other services, while the Moran I tests and the LM error tests are insignificant for these two sectors. Thus, the aforementioned six sectors might be subject to significant spatial interdependencies, which need to be checked through careful discussion of the spatial estimate results.

We find significant spatial autocorrelation in the residuals of the estimates of all sectors when analyzing employment specialization, but investment specialization proved not to be affected by spatial correlation at all for three sectors. For the 11 sectors in which LM error test values exceed LM lag test values, we can confirm a significant and consistent spatial error autocorrelation. It is negative for all of those sectors save textiles.

\section{TABLE 5}

Regression Diagnostics for Spatial Autocorrelation of Employment Specialization (Inverse Squared Distance Matrix)

\begin{tabular}{lccc}
\hline & Moran I & $\begin{array}{c}\text { LM error } \\
\text { test }\end{array}$ & $\begin{array}{c}\text { LM lag } \\
\text { test }\end{array}$ \\
\hline Agricultural, forestry and fishery products & $15.5^{* * *}$ & $71.5^{* * *}$ & $209.2^{* * *}$ \\
\hline Manufactured products & $-4.9^{* * *}$ & $12.9^{* * *}$ & $4.9^{* *}$ \\
Fuel and power products & $-17.4^{* * *}$ & $118.3^{* * *}$ & $12.9^{* * *}$ \\
Ferrous and non-ferrous ores and metals, other than & & & \\
$\quad$ radioactive & $-4.9^{* * *}$ & $13.0^{* * *}$ & $6.8^{* * *}$ \\
Non-metallic minerals and mineral products & $-3.9^{* * *}$ & $9.1^{* * *}$ & 0.5 \\
Chemical products & $-4.9^{* * *}$ & $13.4^{* * *}$ & 2.4 \\
Metal products, machinery, equipment, electrical & & & \\
$\quad$ goods & $-16.9^{* * *}$ & $115.6^{* * *}$ & $41.1^{* * *}$ \\
Transport equipment & $-13.7^{* * *}$ & $77.8^{* * *}$ & $7.1^{* * *}$ \\
Food, beverages, tobacco & $21.6^{* * *}$ & $143.3^{* * *}$ & $129.2^{* * *}$ \\
Textiles and clothing, leather and footwear & $3.9^{* * *}$ & 2.5 & $10.0^{* * *}$ \\
Paper and printing products & $13.8^{* * *}$ & $55.5^{* * *}$ & $70.4^{* * *}$ \\
Products of various industries & -0.7 & 1.3 & $36.6^{* * *}$ \\
Building and construction & & & \\
Services & $-18.6^{* * *}$ & $137.9^{* * *}$ & $82.5^{* * *}$ \\
Recovery, repair, trade, lodging and catering services & $-15.5^{* * *}$ & $98.3^{* * *}$ & $18.9^{* * *}$ \\
Transport and communication services & $-11.6^{* * *}$ & $57.9^{* * *}$ & $13.6^{* * *}$ \\
Services of credit and insurance institutions & -0.1 & 0.6 & $16.1^{* * *}$ \\
Other market services & $5.0^{* * *}$ & $4.6^{* *}$ & $55.5^{* * *}$ \\
Non-market services & & & \\
\hline
\end{tabular}


With respect to those six sectors under consideration for spatial lag dependence according to the inverse squared distance matrix, the identification of the optimal model is less clear. It seems that the spatial error model is superior in the analysis of paper and printing products as well as non-market services. However, it is inferior when investigating products of various industries; other market services; and building and construction as well as agricultural, forestry, and fishery products according to the AIC value (see Table A5). ${ }^{18}$ While the Moran I statistics were insignificant for building and construction as well as other services, we now find a significant positive spatial dependence. Thus, all four sectors for which the spatial lag dependence model turns out to be superior seem to have a positive spatial lag dependence. In economic terms, this would imply that regions benefiting from high employment specialization in the products of various industries, other services, building and construction, or agriculture might exert a positive impact on the specialization of surrounding regions in this sector. However, in all of these cases the analysis with the neighborhood contiguity matrix does not confirm the spatial lag dependence. ${ }^{19}$ As is the case for investments, results concerning spatial interdependencies are thus inconsistent across different spatial weight matrices. While the use of the inverse distance matrix would point to economic spillovers causing spatial lag dependence in four sectors, we are confronted with simple spatial error correlation applying the alternative weight matrix. This leaves us with contradictory outcomes.

Again, the use of the inverse distance matrix implies stronger identification of spatial lag dependence in comparison to the use of the neighborhood contiguity matrix for the 10 nearest neighbors: in the case of SP.GFCF.EU, three sectors in contrast to one sector; in the case of SP.EMP.EU, four in contrast to zero sectors show significant spatial lag dependence with respect to the inverse distance matrix and the neighborhood contiguity matrix, respectively. The inverse distance matrix incorporates the influence of any region, its weight decreasing with increasing distance; the influence implemented according to a neighborhood contiguity matrix cuts off at a certain limit, in our case the eleventh nearest region. It is possible that such a cut-off is too strong an assumption to capture all economic spillovers sufficiently; however, the use of the inverse distance matrix might also overestimate the influence of the surrounding regions.

However, importantly, the results of classical econometric estimates are again mostly robust when controlling for spatial autocorrelation effects. Though we have some changes in the significance of the coefficients (in both ways, either gaining or losing significance), the general results of the recent studies summarized in the first section can be confirmed.

\footnotetext{
${ }^{18}$ In addition, in all those cases, the likelihood ratio test value - checking for the fit of the estimated model - is much higher for the spatial lag model than for the spatial error model.

${ }^{19}$ Results are available from the author upon request.
} 


\section{ECONOMIC IMPACTS OF SPECIALIZATION PATTERNS AND DETERMINANTS}

The spatial econometric estimates presented above allow us to draw conclusions with respect to two main topics: the robustness of the results using classical econometrics and the spatial interaction impacts on regional specialization patterns.

First, we find significant spatial autocorrelation effects for most sectors - irrespective of the results of the analysis of investments and employment. However, these do not influence the results on the economic determinants of sectoral specialization of EU regions, which can thus be assumed to be robust.

The economic determinants identified throughout this analysis differ only slightly when comparing investment and employment specialization. However, in a related study (Stirboeck 2004), some differences are evident when analyzing research intensity as well as comparative advantage variables such as labor cost or productivity differentials. As mentioned above, however, we did not include these (undoubtedly important) explanatory variables in the present analysis due to their restricted availability across time and across regions. Stirboeck (2004) demonstrated that with respect to many sectors, productivity differentials and average regional labor cost differentials as well as research intensities contribute to the explanation of regional specialization patterns in accordance with traditional trade theory. For productivity differentials, this is especially the case with respect to the explanation of investment patterns, whereas regional labor cost differentials and research intensities contribute mainly by explaining employment patterns. The explanation of part of regional specialization patterns by comparative advantages according to trade theory is in line with a uniform allocation of total production across space.

With regard to the variables in this study, relative investment and employment shares in manufacturing sectors are higher close to large markets but not in the administrative centers. The strength of specialization in manufacturing is influenced positively by the market potential of a region (its level of GRP) and negatively by being located in the periphery. This implies that we might be confronted with negative backwash effects for peripheral regions in scale-intensive manufacturing sectors. This is all the more valid since the regional sector-specific economies of scale are, according to Stirboeck (2004), relevant in explaining manufacturing specialization, entailing a further agglomeration potential for scale-intensive sectors.

Although market integration might have been a trigger for further agglomeration, it does not play a particular role for specific sectors. Moreover, we are not confronted with complete agglomeration of one or some sectors. Since the level of specialization is significantly lower in economic centers and large markets (see Stirboeck 2002a), we do not find a concentration of scale-intensive manufacturing sectors in just a very few regions; instead, we see that they are more or less evenly distributed across all centrally located regions. Demand and supply linkages are evidently not so strong as to lead to the 
complete agglomeration of whole sectors in one or few regions. This is also reflected (especially for the manufacturing sectors) in, for most, sectors the insignificant or weak (and not robust) spatial lag dependence we identified.

Country-specific effects remain relevant and are not totally captured by the economic and regional determinants discussed so far. However, only the analysis of employment specialization patterns points to clear country-specific effects: while Italy has lower employment shares in many manufacturing sectors, it has higher shares in the laborintensive sectors of agriculture as well as recovery, repair, trade, lodging, and catering. Indeed, the latter sector might possibly be characterized by spatial interdependence, which is discussed further below. However, this interdependence might be influenced to a large extent by natural conditions such as Italy's coastline and favorable climate and less by economic interactions.

In addition to the lower specialization in manufacturing of Italian regions, peripheral regions exhibit manufacturing shares that are below the EU average. Consistent with this is their higher specialization in the services sectors. Such a stronger specialization in services is similarly evident for peripheral regions and administrative centers alike. However, the quality of specialization is where the differences lie, especially as regards investments. Growth-oriented services sector specialization (chiefly credit and insurance services as well as transport and communication services with respect to investment specialization) is more pronounced in administrative centers while tourism-related services sector specialization is stronger in peripheral regions. However, spatial interaction is not really relevant, as we will summarize in the following.

Second, spatial autocorrelation, though present, is due mostly to spatial error autocorrelation. This is the case for a large number of sectors (FUEL, META, CHEM, METP, TREQ, FOOD, TEXT, PAPE, TRCO, CRED, and NMSE) - irrespective of the factor of production we analyze. In these sectors, we have no evidence of economic interdependencies between neighboring regions. The visible spatial error autocorrelation is simply a sign of potential data problems or regional definitions that do not adequately capture the specific spatial dimension of sectoral specialization patterns. This means that we clearly can reject the assumption of spatial lag dependence of regional specialization in most manufacturing, scale-intensive sectors.

However, there are some exceptions to the prevalence and clearness of the spatial error autocorrelation with respect to some, but not all, labor-intensive sectors. It is thus possible that labor-intensive production or provision of services is positively influenced by the degree of specialization of surrounding regions in some cases.

With respect to investment specialization, these exceptions include the mineral products, various industries, recovery, repair, trade, lodging, and catering services sectors when using the inverse squared distance matrix. The regional investment specialization in one of these three sectors is significantly and positively influenced by that of neighboring regions. According to the spatial association analysis of Section 3, the geographic 
allocation of regions specialized in these sectors shows that the highest specialization in minerals and mineral products for regions in the central parts of Italy and in recovery, repair, trade, lodging, and catering services for the traditional tourist and coastal Italian regions and the island of Corsica. However, the results of a possible spatial lag dependence need not necessarily be due to economic interactions, but might follow from natural conditions like raw material resources or a shared coastline. No clear geographical location patterns are obvious for those regions particularly specialized in various industries (whose spatial lag parameter was only weakly significant, even according to the inverse squared distance matrix).

In addition, the agriculture, building and construction, other services, and once again, various industries sectors seem, according to the inverse distance matrix, to be subject to significant positive spatial interactions of employment specialization. The spatial patterns of employment specialization reveal that the southern Italian regions as well as the western French regions display the highest levels of specialization in agriculture and in building and construction. However, for various other regions - such as many Belgian regions, Luxembourg, and some regions in northern France - a high specialization in other market services is evident. With respect to various industries, geographic patterns are again less clear; but a high employment specialization is, as for investment specialization, to be found in central and eastern France as well as some northern Italian regions.

We thus do not find strong similar regional clustering patterns for those sectors subject to potential spatial lag dependence. First, clusters vary from sector to sector, with one exception. Second, regional clusters of strongly specialized regions potentially exerting spill-overs to neighboring regions are definitely neither located all in the periphery nor all in the core.

\section{REGIONAL DEVELOPMENTS IN THE LIGHT OF SECTORAL SPECIALIZATION AND SPATIAL IMPACTS}

To summarize, the Exploratory Spatial Data Analysis (ESDA) using the Getis-Ord statistics does not identify strong clusters of sectoral specialization across those 56 European regions included in the study. There are a very few general clusters of similarly strong specialization in investment and employment (e.g., specialization in agriculture and in building and construction in southern Italy), but these are not very striking. However, we note that according to the local spatial association analysis, identified clusters of either regional employment or investment specialization of the same sector are in most cases located at different places across space. It thus stands to reason that the regional specialization in labor and capital-intensive production of one sector follows different locational patterns.

We only rarely detect significant spatial interdependencies between the level of sectoral specialization of neighboring regions in the econometric analysis, and importantly the identification of the interdependencies is sensitive to the choice of the spatial weights matrix. With respect to the manufacturing sectors, we can clearly reject 
the assumption of potential spatial lag dependence of regional sectoral specialization due to spillovers or economic interactions.

We also do not find strong or clear negative impacts of economic spillovers or regional interactions of detrimental specialization patterns. First, the spatial clustering of similar sectoral specialization in some rather disadvantaged sectors in the peripheral regions identified in the ESDA analyses is not generally accompanied by significant spatial interdependencies. Agriculture as well as building and construction are the only sectors that are, at least according to the inverse squared distance matrix, marked by significant spatial interdependencies in employment (but not investment) specialization while showing an obvious cluster in some peripheral regions. Second, other sectors possibly subject to spatial interactions are clustered in various geographic locations but not predominantly in the periphery.

However, we have to take note that those few sectors that according to the spatial econometric estimates are potentially exposed to significant spatial interdependencies in regional specialization patterns - agriculture, mineral products, various industries, building and construction, and the services sectors recovery, repair, trade, lodging, catering services, and other services - are quite labor-intensive and cannot be classified as strongly growth-oriented sectors.

In addition, according to the econometric analyses, peripheral regions are significantly more heavily specialized in most services sectors as well as building and construction. Therefore, though we do not identify strong clusters of regional specialization in the local spatial association analyses, peripheral regions might be predominantly affected by the positive spatial interdependencies in employment specialization identified for the building industry and other services as well as in investment specialization identified for recovery, repair, trade, lodging, and catering services. Depending on the nature of these activities, the spatial dependence of specialization might exhibit a disadvantageous and low growth outlook for those regions very far located from the core regions.

Thus, peripheral regions' specialization in building and construction reflects infrastructural activities that are probably regional policy activities and not private sector activities. The quality of the specialization in other services and recovery, repair, trade, lodging, and catering services, however, would have to be assessed on the basis of more precise information, i.e., more highly disaggregated data. Trade and lodging can be assumed to be driven mainly by small enterprises, a result of these peripheral regions' tendency to be located along coasts. Other services contain a rather broad spectrum of economic activities that makes evaluation difficult. These include tourism-related services (such as renting) but also business services (such as advertising and consulting).

We might thus be confronted with some disadvantageous spatial interdependencies in the periphery. These are, however, not very strong and not consistently detectable by the use of different spatial weights matrices. In addition, there is no evidence of favorable 
spatial interdependencies in the center and thus no obvious evidence of a further selfincrease in core-periphery tendencies.

\section{REFERENCES}

Amiti, M., 1999. "Specialization Patterns in Europe," Review of World Economics 135(4), 573-593.

Anselin, L., 1988. Spatial Econometrics: Methods and Models. Kluver: Dordrecht. , 1992. SpaceStat Tutorial - A Workbook for Using SpaceStat in the Analysis of Spatial Data. Available at: www.spacestat.com.

Anselin, L. and R. Florax (eds.), 2003. Advances in Spatial Econometrics, Springer: Berlin.

Balassa, B., 1989. Comparative Advantage, Trade Policy and Economic Development, Harvester Wheatsheaf: Hestfordshire, 18-79.

Baltagi, B.H., 2002. Econometrics, 3rd edition. Springer: Berlin.

Brühlhart, M., 1998. "Trading Places Industrial Specialisation in the European Union," Journal of Common Market Studies 36(3), 319-346.

Combes, P.P. and M. Lafourcade, 2001. "Transport Cost Decline and Regional Inequalities Evidence from France," CEPR Discussion Paper 2984: London.

Eurostat, 1999. "Statistik kurzgefasst," Allgemeine Statistik 1-3. Luxembourg.

Haaland, J.I., H.J. Kind, K.H. Midelfart-Knarvik and J. Torstensson, 1999. What Determines the Economic Geography of Europe? CEPR Discussion Paper 2027: London.

Hallet, M., 2002. "Regional Specialisation and Concentration in the EU," in J.R. Cuadrado-Roura, and M. Parellada (eds.), Regional Convergence in the European Union Facts, Prospects and Policies. Springer: Berlin.

Hirschman, A., 1958. The Strategy of Economic Development. Yale University Press: New Haven.

Kalemli-Ozcan S., B.E. Sorensen, and O. Yosha, 2003. "Risk Sharing and Industrial Specialization: Regional and International Evidence," American Economic Review 93(3), 903-918.

Keilbach, M., 2000. Spatial Knowledge Spillovers and the Dynamics of Agglomeration and Regional Growth, Contributions to Economics. Physica: Heidelberg.

Krieger-Boden, C., 1999. "Nationale und regionale Spezialisierungsmuster im europäischen Integrationsprozeß," Die Weltwirtschaft (2), 234-254.

Krugman, P., 1991. Geography and Trade. MIT Press: Cambridge.

Krugman, P. and A.J. Venables, 1995. "Globalization and the Inequality of Nations," Quarterly Journal of Economics 110(4), 857-880.

Lösch, A., 1940. Die räumliche Ordnung der Wirtschaft. Jena.

Midelfart-Knarvik, K.H., H.G. Overman, S.J. Redding, and A.J. Venables, 2000. "The Location of European Industry." European Commission Economic Papers 142: Brussels.

Molle, W., 1997. "The Economics of European Integration Theory, Practice, Policy," in Peschel, K. (ed.), Regional Growth and Regional Policy Within the Framework of European Integration. Physicca: Heidelberg.

Myrdal, G., 1957. Economic Theory and Under-Developed Regions. London. 
Paluzie, E., J. Pons, and A. Tirado, 2001. "Regional Integration and Specialization Patterns in Spain," Regional Studies 35(4), 285-296.

Quinn, D., 1997. "The Correlates of Change in International Financial Regulation," American Political Science Review 91(3), 531-551.

Stirboeck, C., 2001. "Agglomeration Tendencies in EU Regions: Where Does Capital Go?” ZEW Discussion Paper 01-28: Mannheim. , 2002a. "Explaining the Level of Relative Investment Specialisation: A Spatial Econometric Analysis of EU Regions," ZEW Discussion Paper 02-49: Mannheim. , 2002b. "Relative Specialisation of EU Regions: An Econometric Analysis of Sectoral Gross Fixed Capital Formation," ZEW Discussion Paper 02-36: Mannheim. , 2004. Comparing Investment and Employment Specialisation Patterns of EU Regions, ZEW Discussion Paper 04-43: Mannheim.

Suedekum, J., 2006. "Concentration and Specialisation Trends in Germany Since Reunification," forthcoming in Regional Studies 42.

Thünen, J.H., 1875. Der isolierte Staat in Beziehung auf Landwirtschaft und Nationalökonomie. Berlin.

Venables, A.J., 1996. "Equilibrium Locations of Vertically Linked Industries," International Economic Review 37, 341-359. , 2005. "Economic Geography: Spatial Interactions in the World Economy," forthcoming in B. Weingast and D. Wittman (eds.), Oxford Handbook of Political Economy.

Walz, U., 1999. Dynamics of Regional Integration. Physica: Heidelberg. 


\section{APPENDIX}

\section{TABLE A1}

Abbreviation of NUTS 2 Regions

\begin{tabular}{llllll}
\hline France & \multicolumn{2}{c}{ Italia } & & Belgique & \\
\hline Alsace & ALS & Abruzzo & ABR & Antwerpen & ANT \\
Aquitaine & AQU & Basilicata & BAS & Brabant Wallon & BWA \\
Auvergne & AUV & Calabria & CAL & Bruxelles-Capitale & BRU \\
Basse-Normandie & BNO & Campania & CAM & Hainaut & HAI \\
Bourgogne & BOU & Emilia-Romagna & ERO & Liège & LIE \\
Bretagne & BRT & Friuli-Venezia & FVG & Limburg (B) & LIM \\
Centre (F) & CTR & Giulia & & Luxembourg (B) & LUB \\
Champagne-Ardenne & CHA & Lazio & LAZ & Namur & NAM \\
Corse & CRS & Liguria & LIG & Oost-Vlaanderen & OVL \\
Franche-Comté & FRC & Lombardia & LOM & Vlaams Brabant & VBR \\
Haute-Normandie & HNO & Marche & MAR & West-Vlaanderen & WVL \\
Île de France & IDF & Molise & MOL & & \\
Languedoc-Roussillon & LRO & Piemonte & PIE & & \\
Limousin & LIS & Puglia & PUG & & \\
Lorraine & LOR & Sardegna & SAR & & \\
Midi-Pyrénées & MPY & Sicilia & SIC & & \\
Nord- Pas-de-Calais & NPC & Toscana & TOS & & TEN \\
Pays de la Loire & PDL & Trentino-Alto & TAA & Monoregional & \\
Picardie & PIC & Adige & & Countries & \\
Poitou-Charentes & POI & Umbria & UMB & Danmark & IRE \\
Provence-Alpes-Côte & PAC & Valle d'Aosta & VAO & Ireland & LUX \\
d'Azur & & Veneto & VEN & Luxembourg & \\
Rhône-Alpes & RAL & & & & \\
\hline & & & & & \\
\hline & & & & & \\
\end{tabular}




\section{TABLE A2}

Abbreviation and Data Sources of Variables

\begin{tabular}{lll}
\hline Abbreviation & Variable & Unit \\
\hline Data Source: & Gurostat REGIO Database; yearbooks up to 2000, ESA 79 \\
\hline GFCF & Gross Fixed Capital Formation & Currency: billions of ECU \\
EMP & Total Employment & in 1000 persons \\
PODEN & Population Density & in 1000 inhabitants $/ \mathrm{km} 2$ \\
GRP & Gross Regional Product & Currency: billions of ECU \\
AREA & Regional Size & $\mathrm{km}^{2}$ \\
UEWP & Total Unemployment Rates & \\
\hline Data Source: own construction & \\
\hline DIST & Distance to Centre, index of peripherality population \\
CENTR & Regional dummy set for central region & 1000 km \\
\hline Country & & \\
dummies & \\
\hline Data Source: Quinn (1997) & \\
\hline QUINN_OPE & Indicator of Openness per country \\
NN & \\
\hline
\end{tabular}


TABLE A3

Descriptive Statistics

\begin{tabular}{lcrrrr}
\hline & $\begin{array}{c}\text { Number of } \\
\text { Observations }\end{array}$ & Mean & Std. Dev. & \multicolumn{1}{c}{ Min } & \multicolumn{1}{c}{ Max } \\
\hline Variable & 560 & 0.1 & 0.3 & 0.0 & 1.0 \\
PODEN & 560 & 283.1 & 783.1 & 28.3 & 6062.0 \\
DIST & 560 & 337.2 & 281.3 & 1.0 & 1350.7 \\
GRP & 560 & 35061.6 & 41829.5 & 1441.0 & 329603.0 \\
QUINNN_OPENN & 560 & 12.1 & 1.4 & 10.0 & 14.0 \\
AREA & 560 & 17709.9 & 14035.7 & 161.4 & 70273.1 \\
UEWP & 560 & 9.9 & 4.1 & 1.5 & 23.2 \\
\hline SP.GFCF.EU $;$ & & & & & \\
\hline AGRO & 377 & 2.1 & 1.1 & 0.0 & 5.6 \\
\hline FUEL & 387 & 2.0 & 2.8 & 0.3 & 23.9 \\
META & 355 & 1.1 & 2.2 & 0.0 & 19.8 \\
MINE & 371 & 1.1 & 0.7 & 0.0 & 4.2 \\
CHEM & 370 & 0.5 & 0.4 & 0.0 & 3.1 \\
METP & 371 & 0.5 & 0.3 & 0.0 & 1.3 \\
TREQ & 358 & 0.8 & 1.0 & 0.0 & 10.0 \\
FOOD & 371 & 0.8 & 0.5 & 0.1 & 3.6 \\
TEXT & 364 & 0.7 & 0.7 & 0.0 & 3.8 \\
PAPE & 371 & 0.7 & 0.7 & 0.0 & 6.5 \\
VARI & 371 & 1.1 & 0.7 & 0.1 & 4.7 \\
BUIL & 387 & 0.4 & 0.1 & 0.2 & 1.1 \\
\hline TRLO & 358 & 0.6 & 0.2 & 0.1 & 1.7 \\
TRCO & 363 & 1.4 & 0.6 & 0.4 & 4.0 \\
CRED & 363 & 0.4 & 0.3 & 0.1 & 3.3 \\
OTHS & 358 & 2.0 & 0.4 & 1.2 & 3.3 \\
NMSE & 377 & 0.8 & 0.4 & 0.2 & 2.1 \\
\hline SP.EMP.EU $;$ & & & & & \\
\hline AGRO & 494 & 3.0 & 1.9 & 0.0 & 9.9 \\
\hline FUEL & 425 & 0.3 & 0.2 & 0.1 & 1.9 \\
META & 413 & 0.7 & 0.9 & 0.0 & 6.1 \\
MINE & 418 & 1.1 & 0.6 & 0.1 & 3.3 \\
CHEM & 413 & 0.4 & 0.2 & 0.1 & 1.6 \\
METP & 416 & 0.7 & 0.4 & 0.1 & 1.6 \\
TREQ & 417 & 0.6 & 0.6 & 0.0 & 3.7 \\
FOOD & 418 & 0.8 & 0.3 & 0.2 & 1.9 \\
TEXT & 418 & 1.7 & 1.7 & 0.0 & 8.2 \\
PAPE & 418 & 0.5 & 0.3 & 0.0 & 1.4 \\
VARI & 416 & 1.7 & 0.9 & 0.3 & 5.2 \\
BUIL & 425 & 1.2 & 0.3 & 0.6 & 2.5 \\
\hline TRLO & 416 & 1.3 & 0.2 & 0.9 & 2.0 \\
TRCO & 416 & 0.9 & 0.2 & 0.4 & 1.7 \\
CRED & 416 & 0.4 & 0.3 & 0.1 & 2.1 \\
OTHS & 418 & 0.8 & 0.2 & 0.3 & 1.3 \\
NMSE & 425 & 1.3 & 0.3 & 0.8 & 2.3 \\
\hline
\end{tabular}




\section{TABLE A4}

Spatial Econometric Analysis (Spatial Lag and Spatial Error Model) of Investment Specialization Patterns

\begin{tabular}{|c|c|c|c|c|c|c|}
\hline \multirow{2}{*}{$\begin{array}{l}\text { OLS/Spatial } \\
\text { Lag/Error }\end{array}$} & \multicolumn{3}{|c|}{ AGRO } & \multicolumn{3}{|c|}{ FUEL } \\
\hline & OLS & Lag & Error & OLS & Lag & Error \\
\hline W_SPCFEU & & $0.428^{* * *}$ & & & $-0.503^{* *}$ & \\
\hline CONSTANT & $3.664^{* * *}$ & $2.958^{* * *}$ & $4.514^{* * *}$ & -0.387 & 0.204 & $-0.868^{* *}$ \\
\hline CENTR & $-0.715^{* * *}$ & $-0.851^{* * *}$ & $-0.725^{* * *}$ & $0.609^{* * *}$ & $0.779^{* * *}$ & $1.417^{* * *}$ \\
\hline PODEN & $-6.882^{* * *}$ & $-7.526^{* * *}$ & $-7.366^{* * *}$ & $-1.328^{*}$ & $-1.323^{*}$ & -0.372 \\
\hline DIST & $-1.071^{* * *}$ & $-1.101^{* * *}$ & $-0.537^{* * *}$ & 0.174 & 0.260 & $0.447^{* * *}$ \\
\hline GRP & $0.012^{* * *}$ & $0.015^{* * *}$ & $0.015^{* * *}$ & 0.001 & 0.001 & 0.001 \\
\hline QUINN_OPEN & -0.014 & -0.024 & -0.030 & $0.096^{* * *}$ & $0.099^{* * *}$ & $0.096^{* * *}$ \\
\hline AREA - & $-0.021^{* * *}$ & $-0.024^{* * *}$ & $-0.021^{* * *}$ & $0.012^{* *}$ & $0.011^{*}$ & $0.015^{* * *}$ \\
\hline UEWP & $0.066^{* * *}$ & $0.053^{* * *}$ & 0.011 & $0.097^{* * *}$ & $0.117^{* * *}$ & $0.105^{* * *}$ \\
\hline DUM FRA & $-1.331^{* * *}$ & $-0.975^{* * *}$ & $-1.294^{* * *}$ & $-0.734^{* * *}$ & $-0.926^{* * *}$ & $-0.695^{* * *}$ \\
\hline DUM_IRE & $0.876^{* *}$ & $1.455^{* * *}$ & $1.370^{* * *}$ & $-2.367^{* * *}$ & $-2.736^{* * *}$ & $-3.076^{* * *}$ \\
\hline DUM_DEN & $-1.049^{* * *}$ & $-0.804^{* *}$ & $-1.039^{* * *}$ & $-0.636^{*}$ & $-0.831^{* *}$ & $-1.222^{* * *}$ \\
\hline DUM_LUX & $-1.135^{* * *}$ & $-0.633^{*}$ & $-0.854^{* *}$ & $-0.717^{* *}$ & $-0.853^{* *}$ & $-0.615^{* *}$ \\
\hline LAMBDA & & & $0.929^{* * *}$ & & & $-1.749^{* * *}$ \\
\hline Breusch-Pagan test & & $62.55^{* * *}$ & $53.01^{* * *}$ & & $53.63^{* * *}$ & $77.74^{* * *}$ \\
\hline LR-test & & $12.44^{* * *}$ & $17.63^{* * *}$ & & $6.41^{* *}$ & $53.25^{* * *}$ \\
\hline LM-Error/Lag test & & $14.46^{* * *}$ & $25.09^{* * *}$ & & $19.65^{* * *}$ & 2.43 \\
\hline AIC & 2.118 & 2.090 & 2.071 & 2.176 & 2.165 & 2.035 \\
\hline No. of Obs. & 377 & & & 377 & & \\
\hline OLS/Spatial & & META & & & MINE & \\
\hline Lag/Error & OLS & Lag & Error & OLS & Lag & Error \\
\hline W SPCFEU & & $-1.369^{* * *}$ & & & $0.678^{* * *}$ & \\
\hline CŌNSTANT & $3.532^{* * *}$ & $5.644^{* * *}$ & $5.582^{* * *}$ & $1.903^{* * *}$ & $0.937^{* *}$ & $1.641^{* * *}$ \\
\hline CENTR & $-1.372^{*}$ & $-1.809^{* * *}$ & $-2.130^{* * *}$ & $-0.851^{* * *}$ & $-1.032^{* * *}$ & $-1.003^{* * *}$ \\
\hline PODEN & $-4.319^{* *}$ & $-4.477^{* *}$ & $-11.191^{* * *}$ & $-1.355^{* *}$ & $-1.525^{* * *}$ & $-1.344^{* * *}$ \\
\hline DIST & -0.740 & $-1.121^{* *}$ & $-0.939^{* *}$ & $-0.720^{* * *}$ & $-0.742^{* * *}$ & $-0.649^{* * *}$ \\
\hline GRP & $0.014^{*}$ & $0.016^{* *}$ & $0.039^{* * *}$ & $0.004^{*}$ & $0.005^{* *}$ & $0.004^{* *}$ \\
\hline QUINN_OPEN & -0.070 & -0.086 & $-0.167^{* *}$ & 0.003 & 0.000 & 0.002 \\
\hline AREA & $-0.059^{* * *}$ & $-0.074^{* * *}$ & $-0.126^{* * *}$ & 0.000 & -0.001 & -0.004 \\
\hline UEWP & -0.012 & -0.029 & 0.031 & -0.010 & -0.001 & -0.002 \\
\hline DUM_FRA & 0.470 & $0.955^{* * *}$ & $0.828^{* * *}$ & $-0.740^{* * *}$ & $-0.393^{* * *}$ & $-0.469^{* * *}$ \\
\hline DUM_IRE & $2.985^{*}$ & $5.138^{* * *}$ & $7.185^{* * *}$ & 0.148 & 0.625 & 0.708 \\
\hline DUM DEN & - & & & - & & \\
\hline DUM_LUX & $3.321^{* * *}$ & $3.996^{* * *}$ & $3.512^{* * *}$ & 0.166 & $0.764^{* *}$ & $0.628^{*}$ \\
\hline LAMBDA & & & $-1.875^{* * *}$ & & & $0.799^{* * *}$ \\
\hline Breusch-Pagan test & & $363.81^{* * *}$ & $341.16^{* * *}$ & & $106.76^{* * *}$ & $115.55^{* * *}$ \\
\hline LR-test & & $37.33^{* * *}$ & $72.31^{* * *}$ & & $22.34^{* * *}$ & $18.12^{* * *}$ \\
\hline LM-Error/Lag test & & 0.83 & $29.16^{* * *}$ & & $24.11^{* * *}$ & $6.55^{* *}$ \\
\hline AIC & 4.351 & 4.251 & 4.147 & 1.790 & 1.734 & 1.740 \\
\hline No. of Obs. & 353 & & & 361 & & \\
\hline
\end{tabular}


TABLE A4 (Continued)

\begin{tabular}{|c|c|c|c|c|c|c|}
\hline \multirow{2}{*}{$\begin{array}{l}\text { OLS/Spatial } \\
\text { Lag/Error }\end{array}$} & \multicolumn{3}{|c|}{ CHEM } & \multicolumn{3}{|c|}{ METP } \\
\hline & OLS & Lag & Error & OLS & Lag & Error \\
\hline W_SPCFEU & & 0.110 & & & $-0.462^{* * *}$ & \\
\hline CONSTANT & $0.398^{*}$ & 0.334 & 0.352 & $0.876^{* * *}$ & $1.214^{* * *}$ & $0.962^{* * *}$ \\
\hline CENTR & $-0.551^{* * *}$ & $-0.544^{* * *}$ & $-0.479^{* * *}$ & $-0.705^{* * *}$ & $-0.694^{* * *}$ & $-0.605^{* * *}$ \\
\hline PODEN & -0.430 & -0.450 & -0.554 & -0.010 & 0.094 & 0.132 \\
\hline DIST & $-0.329^{* * *}$ & $-0.331^{* * *}$ & $-0.388^{* * *}$ & $-0.377^{* * *}$ & $-0.358^{* * *}$ & $-0.267^{* * *}$ \\
\hline GRP & $0.005^{* * *}$ & $0.004^{* * *}$ & $0.004^{* * *}$ & $0.003^{* * *}$ & $0.003^{* * *}$ & $0.002^{* * *}$ \\
\hline QUINN_OPEN & 0.009 & 0.009 & 0.012 & 0.000 & 0.000 & 0.002 \\
\hline AREA & -0.002 & -0.002 & 0.000 & $0.003^{*}$ & $0.003^{*}$ & -0.001 \\
\hline UEWP & $0.010^{* *}$ & $0.011^{* *}$ & $0.016^{* * *}$ & $-0.035^{* * *}$ & $-0.045^{* * *}$ & $-0.043^{* * *}$ \\
\hline DUM_FRA & -0.017 & -0.026 & -0.081 & -0.013 & 0.011 & $0.044^{* * *}$ \\
\hline DUM IRE & $0.892^{* * *}$ & $0.847^{* * *}$ & $0.592^{* *}$ & $0.760^{* * *}$ & $0.875^{* * *}$ & $1.021^{* * *}$ \\
\hline DUM DEN & - & & & - & & \\
\hline DUM_LUX & 0.237 & 0.233 & 0.145 & $0.230^{*}$ & 0.168 & 0.103 \\
\hline LAMBDA & & & $0.434^{*}$ & & & $-1.779^{* * *}$ \\
\hline Breusch-Pagan test & & $109.36^{* * *}$ & $115.66^{* * *}$ & & $35.20^{* * *}$ & $19.58^{* *}$ \\
\hline LR-test & & 0.33 & 0.79 & & $12.82^{* * *}$ & $84.35^{* * *}$ \\
\hline LM-Error/Lag test & & 1.99 & $36.11^{* * *}$ & & $26.14^{* * *}$ & $72.02^{* * *}$ \\
\hline AIC & 0.824 & 0.828 & 0.822 & -0.204 & -0.234 & -0.438 \\
\hline No. of Obs. & 360 & & & 361 & & \\
\hline OLS/Spatial & & TREQ & & & FOOD & \\
\hline Lag/Error & OLS & Lag & Error & OLS & Lag & Error \\
\hline W_SPCFEU & & -0.032 & & & -0.261 & \\
\hline CONNTANT & 0.356 & 0.376 & 0.365 & $0.849^{* * *}$ & $1.063^{* * *}$ & $0.915^{* * *}$ \\
\hline CENTR & $-0.567^{*}$ & $-0.567^{*}$ & $-0.565^{*}$ & $-0.872^{* * *}$ & $-0.883^{* * *}$ & $-1.164^{* * *}$ \\
\hline PODEN & -0.982 & -0.960 & -1.011 & $-1.006^{* * *}$ & $-0.899^{* *}$ & $-0.724^{*}$ \\
\hline DIST & $-0.840^{* * *}$ & $-0.849^{* * *}$ & $-0.838^{* * *}$ & $-0.897^{* * *}$ & $-0.948^{* * *}$ & $-1.033^{* * *}$ \\
\hline GRP & 0.004 & 0.004 & 0.004 & $0.003^{* *}$ & $0.003^{* *}$ & $0.002^{*}$ \\
\hline QUINN_OPEN & $0.081^{*}$ & $0.081^{*}$ & $0.081^{*}$ & $0.039^{* *}$ & $0.039^{* *}$ & $0.039^{* * *}$ \\
\hline AREA & $-0.015^{*}$ & $-0.015^{*}$ & $-0.015^{*}$ & -0.003 & -0.003 & -0.003 \\
\hline UEWP & 0.004 & 0.004 & 0.003 & $-0.012^{* *}$ & $-0.014^{* * *}$ & $-0.016^{* * *}$ \\
\hline DUM_FRA & 0.188 & 0.188 & 0.187 & $0.288^{* * *}$ & $0.341^{* * *}$ & $0.289^{* * *}$ \\
\hline DUM_IRE & 0.425 & 0.419 & 0.432 & $2.055^{* * *}$ & $2.132^{* * *}$ & $2.378^{* * *}$ \\
\hline DUM_DEN & - & & & - & & \\
\hline DUM_LUX & -0.484 & -0.474 & -0.499 & 0.216 & 0.238 & 0.227 \\
\hline LAMB̄DA & & & 0.024 & & & $-1.162^{* * *}$ \\
\hline Breusch-Pagan test & & $112.08^{* * *}$ & $111.13^{* * *}$ & & $78.75^{* * *}$ & $76.59^{* * *}$ \\
\hline LR-test & & 0.02 & 0.01 & & $2.99^{*}$ & $35.25^{* * *}$ \\
\hline LM-Error/Lag test & & 1.40 & 1.40 & & $40.15^{* * *}$ & $151.14^{* * *}$ \\
\hline AIC & 2.814 & 2.820 & 2.814 & 0.814 & 0.811 & 0.716 \\
\hline No. of Obs. & 353 & & & 361 & & \\
\hline
\end{tabular}


TABLE A4 (Continued)

\begin{tabular}{|c|c|c|c|c|c|c|}
\hline \multirow{2}{*}{$\begin{array}{l}\text { OLS/Spatial } \\
\text { Lag/Error }\end{array}$} & \multicolumn{3}{|c|}{ TEXT } & \multicolumn{3}{|c|}{ PAPE } \\
\hline & OLS & Lag & Error & OLS & Lag & Error \\
\hline W_SPCFEU & & $-0.388^{*}$ & & & -0.180 & \\
\hline CONNSTANT & $1.550^{* * *}$ & $2.022^{* * *}$ & $1.778^{* * *}$ & $1.291^{* * *}$ & $1.448^{* * *}$ & $1.334^{* * *}$ \\
\hline CENTR & $-1.786^{* * *}$ & $-1.702^{* * *}$ & $-1.451^{* * *}$ & $-0.465^{* *}$ & $-0.435^{* *}$ & -0.174 \\
\hline PODEN & $-0.959^{*}$ & -0.771 & -0.597 & 0.083 & 0.117 & 0.227 \\
\hline DIST & $-0.695^{* * *}$ & $-0.608^{* * *}$ & $-0.644^{* * *}$ & $-0.621^{* * *}$ & $-0.646^{* * *}$ & $-0.598^{* * *}$ \\
\hline GRP & $0.011^{* * *}$ & $0.010^{* * *}$ & $0.007^{* * *}$ & 0.001 & 0.001 & 0.000 \\
\hline QUINN_OPEN & -0.021 & -0.018 & -0.010 & -0.005 & -0.005 & -0.001 \\
\hline AREA & 0.003 & 0.002 & 0.000 & -0.002 & -0.002 & -0.002 \\
\hline UEWP & $-0.015^{*}$ & $-0.028^{* * *}$ & $-0.041^{* * *}$ & $-0.038^{* * *}$ & $-0.042^{* * *}$ & $-0.049^{* * *}$ \\
\hline DUM_FRA & $-0.797^{* * *}$ & $-0.951^{* * *}$ & $-0.804^{* * *}$ & $0.177^{* * *}$ & $0.202^{* * *}$ & $0.191^{* * *}$ \\
\hline DUM_IRE & $0.753^{*}$ & $0.730^{*}$ & $0.804^{* *}$ & 0.647 & 0.663 & 0.459 \\
\hline DUM DEN & - & & & - & & \\
\hline DUM_LUX & $1.950^{* * *}$ & $1.617^{* * *}$ & $1.676^{* * *}$ & -0.397 & -0.410 & $-0.580^{* *}$ \\
\hline LAMB̄DA & & & $-1.437^{* * *}$ & & & $-0.821^{* *}$ \\
\hline Breusch-Pagan test & & $96.11^{* * *}$ & $133.82^{* * *}$ & & $226.94^{* * *}$ & $218.75^{* * *}$ \\
\hline LR-test & & $6.29^{* *}$ & $33.86^{* * *}$ & & 0.74 & $7.48^{* * *}$ \\
\hline LM-Error/Lag test & & 0.18 & $111.97^{* * *}$ & & $4.89^{* *}$ & $46.64^{* * *}$ \\
\hline AIC & 1.697 & 1.685 & 1.603 & 1.651 & 1.654 & 1.630 \\
\hline No. of Obs. & 360 & & & 361 & & \\
\hline OLS/Spatial & & VARI & & & BUIL & \\
\hline Lag/Error & OLS & Lag & Error & OLS & Lag & Error \\
\hline W_SPCFEU & & $0.363^{*}$ & & & $0.553^{* * *}$ & \\
\hline CONSTANT & $1.889^{* * *}$ & $1.366^{* * *}$ & $1.869^{* * *}$ & $0.730^{* * *}$ & $0.528^{* * *}$ & $0.779^{* * *}$ \\
\hline CENTR & $-1.211^{* * *}$ & $-1.222^{* * *}$ & $-1.207^{* * *}$ & $0.087^{* *}$ & $0.102^{* * *}$ & $0.140^{* * *}$ \\
\hline PODEN & -0.355 & -0.546 & -0.371 & $-0.418^{* * *}$ & $-0.459^{* * *}$ & $-0.456^{* * *}$ \\
\hline DIST & $-0.664^{* * *}$ & $-0.689^{* * *}$ & $-0.666^{* * *}$ & $0.054^{* *}$ & 0.038 & 0.040 \\
\hline GRP & 0.002 & 0.003 & 0.002 & $0.001^{* *}$ & $0.001^{* * *}$ & $0.001^{* * *}$ \\
\hline QUINN_OPEN & 0.007 & 0.006 & 0.007 & $-0.028^{* * *}$ & $-0.028^{* * *}$ & $-0.028^{* * *}$ \\
\hline AREA & $0.009^{*}$ & 0.009 & $0.009^{*}$ & -0.001 & -0.001 & -0.001 \\
\hline UEWP & $-0.066^{* * *}$ & $-0.051^{* * *}$ & $-0.063^{* * *}$ & $0.010^{* * *}$ & $0.007^{* * *}$ & $0.005^{* *}$ \\
\hline DUM_FRA & -0.114 & $-0.154^{*}$ & -0.118 & $-0.066^{* * *}$ & $-0.042^{* * *}$ & -0.015 \\
\hline DUM_IRE & 0.552 & 0.451 & 0.536 & $-0.244^{* * *}$ & $-0.210^{* * *}$ & $-0.219^{* * *}$ \\
\hline DUM_DEN & - & & & -0.065 & -0.067 & $-0.090^{*}$ \\
\hline DUM_LUX & $1.640^{* * *}$ & $1.740^{* * *}$ & $1.668^{* * *}$ & $-0.412^{* * *}$ & $-0.152^{* * *}$ & $-0.163^{* * *}$ \\
\hline LAMB̄DA & & & 0.115 & & & $0.889^{* * *}$ \\
\hline Breusch-Pagan test & & $57.98^{* * *}$ & $57.04^{* * *}$ & & $77.35^{* * *}$ & $75.88^{* * *}$ \\
\hline LR-test & & $4.30^{* *}$ & 0.18 & & $9.73^{* * *}$ & $10.22^{* * *}$ \\
\hline LM-Error/Lag test & & $19.34^{* * *}$ & $6.07^{* *}$ & & $18.54^{* * *}$ & $18.59^{* * *}$ \\
\hline AIC & 1.973 & 1.967 & 1.973 & -1.674 & -1.695 & -1.701 \\
\hline No. of Obs. & 361 & & & 377 & & \\
\hline
\end{tabular}


TABLE A4 (Continued)

\begin{tabular}{|c|c|c|c|c|c|c|}
\hline \multirow{2}{*}{$\begin{array}{l}\text { OLS/Spatial } \\
\text { Lag/Error }\end{array}$} & \multicolumn{3}{|c|}{ TRLO } & \multicolumn{3}{|c|}{ TRCO } \\
\hline & OLS & Lag & Error & OLS & Lag & Error \\
\hline W_SPCFEU & & $0.866^{* * *}$ & & & $-0.449^{* *}$ & \\
\hline CONNTANT & $0.754^{* * *}$ & 0.156 & $0.644^{* * *}$ & -0.015 & $0.830^{*}$ & $0.681^{* * *}$ \\
\hline CENTR & $0.135^{* *}$ & $0.205^{* * *}$ & $0.239^{* * *}$ & $1.612^{* * *}$ & $1.529^{* * *}$ & $1.556^{* * *}$ \\
\hline PODEN & $0.535^{* * *}$ & $0.556^{* * *}$ & $0.512^{* * *}$ & $2.698^{* * *}$ & $2.299^{* * *}$ & 0.464 \\
\hline DIST & $0.210^{* * *}$ & $0.163^{* * *}$ & $0.160^{* * *}$ & $0.461^{* * *}$ & $0.513^{* * *}$ & $0.698^{* * *}$ \\
\hline GRP & $-0.002^{* * *}$ & $-0.002^{* * *}$ & $-0.002^{* * *}$ & $-0.011^{* * *}$ & $-0.010^{* * *}$ & -0.001 \\
\hline QUINN_OPEN & -0.011 & -0.008 & -0.007 & $0.106^{* * *}$ & $0.099^{* * *}$ & $0.068^{* * *}$ \\
\hline AREA & $0.005^{* * *}$ & $0.005^{* * *}$ & $0.005^{* * *}$ & $0.016^{* * *}$ & $0.013^{* * *}$ & -0.003 \\
\hline UEWP & $-0.025^{* * *}$ & $-0.014^{* * *}$ & $-0.011^{* * *}$ & $-0.026^{* * *}$ & $-0.029^{* * *}$ & $-0.029^{* * *}$ \\
\hline DUM_FRA & $-0.049^{* *}$ & -0.035 & -0.029 & $-0.341^{* * *}$ & $-0.453^{* * *}$ & $-0.275^{* * *}$ \\
\hline DUM IRE & - & & & $-1.249^{* * *}$ & $-1.131^{* * *}$ & -0.300 \\
\hline DUM_DEN & - & & & - & & \\
\hline DUM_LUX & -0.111 & -0.057 & -0.040 & $-1.623^{* * *}$ & $-1.711^{* * *}$ & $-1.555^{* * *}$ \\
\hline LAMBDA & & & $0.954^{* * *}$ & & & $-1.934^{* * *}$ \\
\hline Breusch-Pagan test & & $179.82^{* * *}$ & $186.18^{* * *}$ & & $91.89^{* * *}$ & $143.35^{* * *}$ \\
\hline LR-test & & $36.34^{* * *}$ & $33.29^{* * *}$ & & $5.57^{* *}$ & $42.41^{* * *}$ \\
\hline LM-Error/Lag test & & $22.56^{* * *}$ & 1.46 & & $3.03^{*}$ & $34.71^{* * *}$ \\
\hline AIC & -0.430 & -0.526 & -0.523 & 1.219 & 1.209 & 1.102 \\
\hline No. of Obs. & 358 & & & 363 & & \\
\hline OLS/Spatial & & CRED & & & OTHS & \\
\hline Lag/Error & OLS & Lag & Error & OLS & Lag & Error \\
\hline W_SPCFEU & & $-0.097^{* * *}$ & & & $0.691^{* * *}$ & \\
\hline CONSTANT & $0.352^{* * *}$ & $0.392^{* * *}$ & $0.338^{* * *}$ & $2.642^{* * *}$ & $1.381^{* * *}$ & $3.368^{* * *}$ \\
\hline CENTR & $0.086^{* * *}$ & $0.077^{* *}$ & $0.086^{* * *}$ & $0.270^{* * *}$ & $0.214^{* *}$ & 0.035 \\
\hline PODEN & $0.476^{* * *}$ & $0.473^{* * *}$ & $0.447^{* * *}$ & $1.392^{* * *}$ & $1.583^{* * *}$ & $1.404^{* * *}$ \\
\hline DIST & 0.016 & 0.009 & -0.002 & $0.257^{* * *}$ & $0.332^{* * *}$ & $0.400^{* * *}$ \\
\hline GRP & $-0.001^{* *}$ & $-0.001^{* *}$ & $-0.001^{* *}$ & $-0.002^{* *}$ & $-0.002^{* *}$ & -0.001 \\
\hline QUINN_OPEN & $-0.008^{*}$ & $-0.008^{*}$ & $-0.009^{* *}$ & $-0.098^{* * *}$ & $-0.100^{* * *}$ & $-0.107^{* * *}$ \\
\hline AREA & $0.004^{* * *}$ & $0.004^{* * *}$ & $0.003^{* * *}$ & 0.001 & 0.000 & 0.000 \\
\hline UEWP & $-0.010^{* * *}$ & $-0.011^{* * *}$ & $-0.008^{* * *}$ & $0.020^{* * *}$ & $0.008^{* *}$ & -0.006 \\
\hline DUM_FRA & $0.075^{* * *}$ & $0.090^{* * *}$ & $0.104^{* * *}$ & $0.153^{* * *}$ & $0.128^{* * *}$ & $0.250^{* * *}$ \\
\hline DUM_IRE & $0.480^{* * *}$ & $0.501^{* * *}$ & $0.528^{* * *}$ & - & & \\
\hline DUM_DEN & - & & & - & & \\
\hline DUM_LUX & $2.448^{* * *}$ & $2.449^{* * *}$ & $2.547^{* * *}$ & $-0.841^{* * *}$ & $-0.957^{* * *}$ & $-0.776^{* * *}$ \\
\hline LAMBDA & & & $0.836^{* * *}$ & & & $0.979^{* * *}$ \\
\hline Breusch-Pagan test & & $214.02^{* * *}$ & $263.41^{* * *}$ & & $32.09^{* * *}$ & $28.76^{* * *}$ \\
\hline LR-test & & $7.02^{* * *}$ & $12.58^{* * *}$ & & $15.71^{* * *}$ & $63.83^{* * *}$ \\
\hline LM-Error/Lag test & & $8.28^{* * *}$ & 2.60 & & $35.49^{* * *}$ & 1.57 \\
\hline $\mathrm{AIC}$ & 1.771 & -1.785 & -1.806 & 0.165 & 0.127 & -0.013 \\
\hline No. of Obs. & 363 & & & 358 & & \\
\hline
\end{tabular}


TABLE A4 (Continued)

\begin{tabular}{|c|c|c|c|}
\hline \multirow{2}{*}{$\begin{array}{l}\text { OLS/Spatial } \\
\text { Lag/Error }\end{array}$} & \multicolumn{3}{|c|}{ NMSE } \\
\hline & OLS & Lag & Error \\
\hline W_SPCFEU & & -0.254 & \\
\hline CONNSTANT & $0.481^{* * *}$ & $0.628^{* * *}$ & $0.470^{* * *}$ \\
\hline CENTR & 0.120 & 0.102 & -0.005 \\
\hline PODEN & $-0.528^{* * *}$ & $-0.533^{* *}$ & $-1.019^{* * *}$ \\
\hline DIST & $0.473^{* * *}$ & $0.480^{* * *}$ & $0.462^{* * *}$ \\
\hline GRP & -0.001 & -0.001 & 0.001 \\
\hline QUINN_OPEN & 0.010 & 0.010 & 0.005 \\
\hline AREA & $-0.008^{* * *}$ & $-0.007^{* * *}$ & $-0.006^{* * *}$ \\
\hline UEWP & $0.008^{* * *}$ & $0.009^{* * *}$ & $0.015^{* * *}$ \\
\hline DUM_FRA & $0.503^{* * *}$ & $0.568^{* * *}$ & $0.486^{* * *}$ \\
\hline DUM_IRE & 0.199 & 0.212 & 0.086 \\
\hline DUM_DEN & $0.473^{* * *}$ & $0.497^{* * *}$ & $0.384^{* * *}$ \\
\hline DUM_LUX & $0.575^{* * *}$ & $0.681^{* * *}$ & $0.570^{* * *}$ \\
\hline LAMB̄DA & & & $-1.454^{* * *}$ \\
\hline Breusch-Pagan test & & $136.53^{* * *}$ & $113.24^{* * *}$ \\
\hline LR-test & & $3.50^{*}$ & $47.61^{* * *}$ \\
\hline LM-Error/Lag test & & $15.24^{* * *}$ & $138.98^{* * *}$ \\
\hline AIC & 0.018 & 0.014 & -0.108 \\
\hline No. of Obs. & 377 & & \\
\hline
\end{tabular}




\section{TABLE A5}

Spatial Econometric Analysis (Spatial Lag and Spatial Error Model) of Employment Specialization Patterns

\begin{tabular}{|c|c|c|c|c|c|c|}
\hline \multirow{2}{*}{$\begin{array}{l}\text { OLS/Spatial } \\
\text { Lag/Error }\end{array}$} & \multicolumn{3}{|c|}{ AGRO } & \multicolumn{3}{|c|}{ FUEL } \\
\hline & OLS & Lag & Error & OLS & Lag & Error \\
\hline W_SPEMEU & & $0.896^{* * *}$ & & & -0.307 & \\
\hline CONSTANT & $1.744^{* * *}$ & 0.105 & $16.404^{* * *}$ & 0.098 & $0.165^{*}$ & 0.093 \\
\hline CENTR & -0.103 & $-0.955^{* * *}$ & $-0.766^{* * *}$ & 0.053 & 0.050 & $0.118^{* *}$ \\
\hline PODEN & $-0.252^{* * *}$ & -0.087 & -0.044 & $-0.036^{* *}$ & $-0.039^{* * *}$ & $-0.102^{* * *}$ \\
\hline DIST & $0.000^{* *}$ & $-0.642^{* * *}$ & -0.298 & $0.000^{* * *}$ & $0.135^{* * *}$ & $0.198^{* * *}$ \\
\hline GRP & $-0.017^{* * *}$ & $-0.014^{* * *}$ & $-0.013^{* * *}$ & 0.000 & 0.000 & $0.001^{* * *}$ \\
\hline QUINN_OPEN & $0.113^{* * *}$ & $0.066^{* *}$ & $0.057^{*}$ & 0.003 & 0.003 & 0.000 \\
\hline AREA & $0.012^{*}$ & 0.001 & -0.001 & $-0.003^{* *}$ & $-0.003^{* *}$ & $-0.002^{*}$ \\
\hline UEWP & $0.165^{* * *}$ & $0.068^{* * *}$ & $0.053^{* * *}$ & $0.009^{* * *}$ & $0.009^{* * *}$ & $0.006^{* * *}$ \\
\hline DUM_FRA & $-1.385^{* * *}$ & $-0.225^{*}$ & $-0.777^{* * *}$ & $0.123^{* * *}$ & $0.139^{* * *}$ & $0.111^{* * *}$ \\
\hline DUM_IRE & -0.869 & $2.318^{* * *}$ & $2.063^{* * *}$ & $0.243^{* *}$ & $0.258^{* *}$ & $0.187^{*}$ \\
\hline DUM_DEN & $-1.274^{* *}$ & $0.766^{*}$ & 0.425 & 0.019 & 0.035 & -0.058 \\
\hline DUM_LUX & $-2.091^{* * *}$ & $-0.988^{* *}$ & $-1.322^{* * *}$ & -0.004 & 0.018 & -0.109 \\
\hline DUM BEL & $-2.950^{* * *}$ & $-0.895^{* * *}$ & $-0.949^{* *}$ & $0.128^{* * *}$ & $0.153^{* * *}$ & $0.239^{* * *}$ \\
\hline LAMBDA & & & $0.988^{* * *}$ & & & $-1.269^{* * *}$ \\
\hline Breusch-Pagan test & & $181.598^{* * *}$ & $232.323^{* * *}$ & & $455.550^{* * *}$ & $396.535^{* * *}$ \\
\hline LR-test & & $146.902^{* * *}$ & $155.176^{* * *}$ & & $2.744^{*}$ & $19.711^{* * *}$ \\
\hline LM-Error/Lag test & & $188.392^{* * *}$ & 0.029 & & 0.555 & $63.488^{* * *}$ \\
\hline $\mathrm{AIC}$ & 3.007 & 2.713 & 2.774 & -0.628 & -0.629 & -0.674 \\
\hline No. of Obs. & 494 & & & 425 & & \\
\hline \multirow{2}{*}{$\begin{array}{l}\text { OLS/Spatial } \\
\text { Lag/Error }\end{array}$} & \multicolumn{3}{|c|}{ Meta } & \multicolumn{3}{|c|}{ Mine } \\
\hline & OLS & Lag & Error & OLS & Lag & Error \\
\hline W_SPEMEU & & $-0.234^{* * *}$ & & & -0.304 & \\
\hline CONSTANT & $1.050^{* * *}$ & $1.232^{* * *}$ & $1.164^{* * *}$ & $1.321^{* * *}$ & $1.740^{* * *}$ & $1.531^{* * *}$ \\
\hline CENTR & $-0.575^{* * *}$ & $-0.553^{* * *}$ & $-0.432^{* *}$ & $-0.450^{* *}$ & $-0.400^{* *}$ & $-0.304^{*}$ \\
\hline PODEN & $-0.090^{*}$ & $-0.100^{*}$ & $-0.163^{* * *}$ & $-0.104^{* *}$ & $-0.120^{* * *}$ & $-0.317^{* * *}$ \\
\hline DIST & 0.000 & $0.318^{*}$ & $0.692^{* * *}$ & $0.000^{* * *}$ & $-0.502^{* * *}$ & $-0.572^{* * *}$ \\
\hline GRP & 0.002 & $0.002^{*}$ & $0.003^{* * *}$ & $-0.002^{* *}$ & $-0.002^{* *}$ & $-0.002^{* *}$ \\
\hline QUINN_OPEN & -0.012 & -0.014 & -0.021 & $0.032^{*}$ & $0.031^{*}$ & 0.024 \\
\hline AREA & $-0.019^{* * *}$ & $-0.021^{* * *}$ & $-0.029^{* * *}$ & 0.001 & 0.002 & $0.010^{* * *}$ \\
\hline UEWP & $-0.016^{* *}$ & $-0.020^{* * *}$ & $-0.028^{* * *}$ & $-0.011^{*}$ & $-0.014^{* *}$ & $-0.029^{* * *}$ \\
\hline DUM_FRA & $0.194^{* *}$ & $0.271^{* * *}$ & $0.277^{* * *}$ & $-0.406^{* * *}$ & $-0.494^{* * *}$ & $-0.531^{* * *}$ \\
\hline DUM IRE & $1.396^{* * *}$ & $1.582^{* * *}$ & $2.024^{* * *}$ & 0.251 & 0.084 & -0.390 \\
\hline DUM DEN & $0.548^{*}$ & $0.672^{* *}$ & $0.776^{* * *}$ & -0.324 & $-0.465^{*}$ & $-0.820^{* * *}$ \\
\hline DUM_LUX & $4.839^{* * *}$ & $4.791^{* * *}$ & $3.985^{* * *}$ & 0.292 & 0.048 & $-0.636^{* *}$ \\
\hline DUM_BEL & $0.393^{* * *}$ & $0.581^{* * *}$ & $0.654^{* * *}$ & $-0.431^{* * *}$ & $-0.531^{* * *}$ & $-0.215^{* * *}$ \\
\hline LAMBDA & & & $-1.414^{* * *}$ & & & $-1.376^{* * *}$ \\
\hline Breusch-Pagan test & & $104.595^{* * *}$ & $84.380^{* * *}$ & & $125.747^{* * *}$ & $85.120^{* * *}$ \\
\hline LR-test & & $10.825^{* * *}$ & $81.105^{* * *}$ & & $3.699^{*}$ & $28.943^{* * *}$ \\
\hline LM-Error/Lag test & & $35.364^{* * *}$ & $197.123^{* * *}$ & & 0.112 & $83.495^{* * *}$ \\
\hline AIC & 1.889 & 1.868 & 1.693 & 1.599 & 1.595 & 1.530 \\
\hline No. of Obs. & 413 & & & 418 & & \\
\hline
\end{tabular}


TABLE A5 (Continued)

\begin{tabular}{|c|c|c|c|c|c|c|}
\hline \multirow{2}{*}{$\begin{array}{l}\text { OLS/Spatial } \\
\text { Lag/Error }\end{array}$} & \multicolumn{3}{|c|}{ CHEM } & \multicolumn{3}{|c|}{ METP } \\
\hline & OLS & Lag & Error & OLS & Lag & Error \\
\hline W_SPEMEU & & 0.098 & & & 0.126 & \\
\hline CONSTANT & $0.279^{* * *}$ & $0.240^{*}$ & $0.248^{* * *}$ & $1.062^{* * *}$ & $0.941^{* * *}$ & $1.215^{* * *}$ \\
\hline CENTR & $-0.250^{* * *}$ & $-0.245^{* * *}$ & $-0.158^{* *}$ & $-0.850^{* * *}$ & $-0.848^{* * *}$ & $-0.891^{* * *}$ \\
\hline PODEN & -0.010 & -0.014 & $0.056^{* * *}$ & $0.103^{* * *}$ & $0.101^{* * *}$ & $0.057^{* * *}$ \\
\hline DIST & $0.000^{* * *}$ & $-0.917^{* * *}$ & -0.029 & $0.000^{* * *}$ & $-0.434^{* * *}$ & $-0.298^{* * *}$ \\
\hline GRP & $0.003^{* * *}$ & $0.003^{* * *}$ & $0.003^{* * *}$ & $0.006^{* * *}$ & $0.006^{* * *}$ & $0.006^{* * *}$ \\
\hline QUINN_OPEN & 0.004 & 0.004 & 0.001 & $-0.019^{* *}$ & $-0.017^{* *}$ & $-0.024^{* * *}$ \\
\hline AREA & -0.001 & -0.001 & $-0.003^{* *}$ & $0.003^{* *}$ & $0.004^{* *}$ & -0.002 \\
\hline UEWP & 0.000 & 0.000 & -0.002 & $-0.028^{* * *}$ & $-0.025^{* * *}$ & $-0.037^{* * *}$ \\
\hline DUM_FRA & $0.070^{* *}$ & $0.061^{*}$ & $0.113^{* * *}$ & $0.185^{* * *}$ & $0.170^{* * *}$ & $0.240^{* * *}$ \\
\hline DUM_IRE & $0.289^{*}$ & $0.258^{*}$ & $0.440^{* * *}$ & $0.763^{* * *}$ & $0.718^{* * *}$ & $1.175^{* * *}$ \\
\hline DUM DEN & 0.048 & 0.028 & 0.085 & $0.517^{* * *}$ & $0.503^{* * *}$ & $0.720^{* * *}$ \\
\hline DUM_LUX & 0.061 & 0.063 & $-0.223^{* *}$ & $0.602^{* * *}$ & $0.653^{* * *}$ & $0.222^{*}$ \\
\hline DUM_BEL & $0.199^{* * *}$ & $0.185^{* * *}$ & $0.230^{* * *}$ & -0.054 & -0.048 & -0.017 \\
\hline LAMBDA & & & $-1.496^{* * *}$ & & & $-1.263^{* * *}$ \\
\hline Breusch-Pagan test & & $209.551^{* * * *}$ & $109.960^{* * *}$ & & $59.594^{* * *}$ & $83.716^{* * *}$ \\
\hline LR-test & & 0.366 & $51.509^{* * *}$ & & 1.373 & $26.925^{* * *}$ \\
\hline LM-Error/Lag test & & $32.220^{* * *}$ & $40.388^{* * *}$ & & $47.915^{* * *}$ & $88.465^{* * *}$ \\
\hline $\mathrm{AIC}$ & -0.213 & -0.209 & -0.338 & 0.011 & 0.012 & -0.054 \\
\hline No. of Obs. & 413 & & & 416 & & \\
\hline OLS/Spatial & & TREQ & & & FOOD & \\
\hline Lag/Error & OLS & Lag & Error & OLS & Lag & Error \\
\hline W_SPEMEU & & $-0.516^{* * *}$ & & & -0.208 & \\
\hline CONSTANT & $0.858^{* * *}$ & $1.223^{* * *}$ & $0.966^{* * *}$ & $0.918^{* * *}$ & $1.070^{* * *}$ & $0.956^{* * *}$ \\
\hline CENTR & $-0.599^{* * *}$ & $-0.635^{* * *}$ & $-0.670^{* * *}$ & $-0.532^{* * *}$ & $-0.539^{* * *}$ & $-0.645^{* * *}$ \\
\hline PODEN & 0.072 & $0.072^{*}$ & -0.001 & 0.011 & 0.014 & 0.005 \\
\hline DIST & $0.000^{* * *}$ & $-0.433^{* * *}$ & $-0.210^{* *}$ & $0.000^{* * *}$ & $-0.513^{* * *}$ & $-0.563^{* * *}$ \\
\hline GRP & $0.004^{* * *}$ & 0.004 & $0.004^{* * *}$ & 0.000 & 0.000 & 0.000 \\
\hline QUINN_OPEN & -0.010 & -0.012 & -0.013 & 0.001 & 0.001 & 0.001 \\
\hline AREA - & $-0.009^{* *}$ & $-0.011^{* * *}$ & $-0.019^{* * *}$ & 0.002 & 0.002 & 0.001 \\
\hline UEWP & -0.005 & -0.008 & $-0.008^{*}$ & $-0.017^{* * *}$ & $-0.017^{* * *}$ & $-0.016^{* * *}$ \\
\hline DUM_FRA & $0.574^{* * *}$ & $0.715^{* * *}$ & $0.702^{* * *}$ & $0.442^{* * *}$ & $0.495^{* * *}$ & $0.436^{* * *}$ \\
\hline DUM_IRE & $0.650^{*}$ & $0.910^{* * *}$ & $1.383^{* * *}$ & $1.082^{* * *}$ & $1.136^{* * *}$ & $1.206^{* * *}$ \\
\hline DUM_DEN & 0.346 & $0.485^{*}$ & $0.742^{* * *}$ & $0.813^{* * *}$ & $0.846^{* * *}$ & $0.915^{* * *}$ \\
\hline DUM_LUX & -0.056 & -0.151 & $-0.576^{* *}$ & $0.315^{* * *}$ & $0.339^{* * *}$ & $0.211^{* *}$ \\
\hline DUM_BEL & -0.019 & 0.016 & 0.032 & $0.156^{* * *}$ & $0.193^{* * *}$ & $0.137^{* * *}$ \\
\hline LAMBDA & & & $-1.199^{* * *}$ & & & $-0.952^{* * *}$ \\
\hline Breusch-Pagan test & & $73.754^{* * *}$ & $84.388^{* * *}$ & & $78.341^{* * *}$ & $90.496^{* * *}$ \\
\hline LR-test & & $15.034^{* * *}$ & $50.929^{* * *}$ & & $3.232^{*}$ & $32.050^{* * *}$ \\
\hline LM-Error/Lag test & & 0.017 & $163.045^{* * *}$ & & $24.752^{* * *}$ & $114.541^{* * *}$ \\
\hline AIC & 1.519 & 1.488 & 1.397 & -0.250 & -0.253 & -0.327 \\
\hline No. of Obs. & 417 & & & 418 & & \\
\hline
\end{tabular}


TABLE A5 (Continued)

\begin{tabular}{|c|c|c|c|c|c|c|}
\hline \multirow{2}{*}{$\begin{array}{l}\text { OLS/Spatial } \\
\text { Lag/Error }\end{array}$} & \multicolumn{3}{|c|}{ TEXT } & \multicolumn{3}{|c|}{ PAPE } \\
\hline & OLS & Lag & Error & OLS & Lag & Error \\
\hline W_SPEMEU & & $0.792^{* * *}$ & & & $0.289^{* *}$ & \\
\hline CONNSTANT & $3.987^{* * *}$ & $1.147^{*}$ & $3.662^{* *}$ & $0.878^{* * *}$ & $0.669^{* * *}$ & $0.658^{* * *}$ \\
\hline CENTR & $-3.978^{* * *}$ & $-4.462^{* * *}$ & $-4.456^{* * *}$ & $-0.183^{* * *}$ & $-0.186^{* * *}$ & $-0.228^{* * *}$ \\
\hline PODEN & $0.534^{* * *}$ & $0.622^{* * *}$ & $0.701^{* * *}$ & $0.044^{* * *}$ & $0.000^{* *}$ & 0.001 \\
\hline DIST & $-0.003^{* * *}$ & $-2.649^{* * *}$ & $-2.340^{* * *}$ & $0.000^{* * *}$ & $-0.399^{* * *}$ & $-0.407^{* * *}$ \\
\hline GRP & $0.013^{* * *}$ & $0.016^{* * *}$ & $0.018^{* * *}$ & $0.003^{* * *}$ & $0.000^{* * * *}$ & $0.004^{* * *}$ \\
\hline QUINN_OPEN & 0.010 & 0.025 & 4.681 & $-0.015^{* *}$ & $-0.014^{* *}$ & $-0.013^{* *}$ \\
\hline AREA & $0.020^{* *}$ & $0.025^{* * *}$ & $0.022^{* * *}$ & 0.001 & 0.000 & 0.002 \\
\hline UEWP & $-0.119^{* * *}$ & $-0.068^{* * *}$ & $-0.100^{* * *}$ & $-0.024^{* * *}$ & $-0.020^{* * *}$ & $-0.017^{* * *}$ \\
\hline DUM_FRA & $-1.385^{* * *}$ & $-0.560^{* * *}$ & 0.040 & $0.220^{* * *}$ & $0.171^{* * *}$ & $0.143^{* * *}$ \\
\hline DUM_IRE & 1.201 & $1.966^{* *}$ & $2.927^{* * *}$ & $0.419^{* * *}$ & $0.340^{* * *}$ & $0.264^{* *}$ \\
\hline DUM_DEN & -0.612 & 0.420 & 0.863 & $0.295^{* * *}$ & $0.255^{* * *}$ & $0.095^{* *}$ \\
\hline DUM LUE & 0.147 & $2.784^{* * *}$ & $3.348^{* * *}$ & 0.018 & 0.059 & 0.059 \\
\hline DUM_BEL & $-2.021^{* * *}$ & $-0.682^{* * *}$ & -0.001 & $0.156^{* * *}$ & $0.091^{* *}$ & -0.095 \\
\hline LAMBDA & & & $0.952^{* * *}$ & & & $0.839^{* * *}$ \\
\hline Breusch-Pagan test & & $157.846^{* * 2 *}$ & $146.692^{* * *}$ & & $134.212^{* * *}$ & $129.379^{* * *}$ \\
\hline LR-test & & $52.460^{* * *}$ & $67.145^{* * *}$ & & $6.340^{* *}$ & $23.271^{* * *}$ \\
\hline LM-Error/Lag test & & $55.413^{* * *}$ & $24.655^{* * *}$ & & $5.673^{* *}$ & $51.590^{* * *}$ \\
\hline $\mathrm{AIC}$ & 3.331 & 3.210 & 3.170 & -0.512 & -0.522 & -0.567 \\
\hline No. of Obs. & 418 & & & 418 & & \\
\hline \multirow{2}{*}{$\begin{array}{l}\text { OLS/Spatial } \\
\text { Lag/Error }\end{array}$} & \multicolumn{3}{|c|}{ VARI } & \multicolumn{3}{|c|}{ BUIL } \\
\hline & OLS & Lag & Error & OLS & Lag & Error \\
\hline W_SPEMEU & & $0.791^{* * *}$ & & & $0.453^{* * *}$ & \\
\hline CONSTANT & $3.061^{* * *}$ & $1.164^{* * *}$ & $2.894^{* * *}$ & $0.581^{* * *}$ & 0.185 & $0.403^{* * *}$ \\
\hline CENTR & $-0.325^{* * *}$ & $-1.351^{* * *}$ & $-1.206^{* * *}$ & $0.132^{*}$ & 0.098 & 0.104 \\
\hline PODEN & 0.046 & 0.052 & 0.084 & $-0.128^{* * *}$ & $-0.117^{* * *}$ & $-0.120^{* * *}$ \\
\hline DIST & $-0.001^{* * *}$ & $-0.763^{* * *}$ & $-0.650^{* * *}$ & $0.001^{* * *}$ & $0.467^{* * *}$ & $0.467^{* * *}$ \\
\hline GRP & 0.002 & $0.003^{* *}$ & $0.003^{* *}$ & $-0.001^{* * *}$ & $-0.001^{* * *}$ & $-0.001^{* *}$ \\
\hline QUINN_OPEN & -0.031 & -0.015 & -0.022 & $0.020^{* * *}$ & $0.016^{* *}$ & $0.026^{* * *}$ \\
\hline AREA & $0.019^{* * *}$ & $0.018^{* * *}$ & $0.021^{* * *}$ & $-0.007^{* * *}$ & $-0.007^{* * *}$ & $-0.007^{* * *}$ \\
\hline UEWP & $-0.100^{* * *}$ & $-0.062^{* * *}$ & $-0.074^{* * *}$ & $0.039^{* * *}$ & $0.029^{* * *}$ & $0.053^{* * *}$ \\
\hline DUM_FRA & -0.136 & -0.131 & -0.008 & 0.032 & $0.058^{*}$ & $0.043^{*}$ \\
\hline DUM_IRE & 0.278 & 0.091 & 0.080 & 0.068 & 0.209 & 0.039 \\
\hline DUM_DEN & 0.140 & 0.190 & 0.088 & $0.239^{* *}$ & $0.284^{* * *}$ & $0.271^{* * *}$ \\
\hline DUM_LUX & 0.691 & $1.075^{* * *}$ & $1.060^{* *}$ & $0.631^{* * *}$ & $0.574^{* * *}$ & $0.810^{* * *}$ \\
\hline DUM_BEL & $-0.347^{* *}$ & -0.007 & 0.154 & 0.042 & $0.074^{*}$ & 0.021 \\
\hline LAMB̄DA & & & $0.865^{* * *}$ & & & $-1.106^{* * *}$ \\
\hline Breusch-Pagan test & & $84.112^{* * *}$ & $78.926^{* * *}$ & & $127.623^{* * *}$ & $89.657^{* * *}$ \\
\hline LR-test & & $39.543^{* * *}$ & $30.240^{* * *}$ & & $22.883^{* * *}$ & $10.491^{* * *}$ \\
\hline LM-Error/Lag test & & $25.302^{* * *}$ & 0.151 & & $120.852^{* * *}$ & $201.569^{* * *}$ \\
\hline AIC & 2.344 & 2.254 & 2.272 & -0.148 & -0.198 & -0.173 \\
\hline No. of Obs. & 416 & & & 425 & & \\
\hline
\end{tabular}


TABLE A5 (Continued)

\begin{tabular}{|c|c|c|c|c|c|c|}
\hline \multirow{2}{*}{$\begin{array}{l}\text { OLS/Spatial } \\
\text { Lag/Error }\end{array}$} & \multicolumn{3}{|c|}{ TRLO } & \multicolumn{3}{|c|}{ TRCO } \\
\hline & OLS & Lag & Error & OLS & Lag & Error \\
\hline W_SPEMEU & & $-0.950^{* * * *}$ & & & $-0.488^{* *}$ & \\
\hline CONSTANT & $1.662^{* * *}$ & $3.002^{* * *}$ & $1.605^{* * *}$ & $0.844^{* * *}$ & $1.313^{* * *}$ & $0.871^{* * *}$ \\
\hline CENTR & 0.066 & 0.042 & $0.108^{* *}$ & $0.347^{* * *}$ & $0.319^{* * *}$ & $0.397^{* * *}$ \\
\hline PODEN & -0.005 & 0.016 & $0.004^{* * *}$ & $-0.036^{* *}$ & $0.000^{* *}$ & $0.000^{*}$ \\
\hline DIST & $0.000^{* * *}$ & $0.394^{* * *}$ & $0.327^{* * *}$ & $0.000^{* * *}$ & $0.211^{* * *}$ & $0.263^{* * *}$ \\
\hline GRP & $-0.001^{* *}$ & 0.000 & 0.000 & $0.001^{* * *}$ & $0.000^{* * *}$ & $0.000^{* * *}$ \\
\hline QUINN_OPEN & $-0.015^{* * *}$ & $-0.017^{* * *}$ & $-0.016^{* * *}$ & 0.004 & 0.002 & -0.001 \\
\hline AREA & $-0.002^{* *}$ & $-0.002^{* *}$ & 0.000 & $-0.005^{* * *}$ & $0.000^{* * *}$ & $0.000^{* * *}$ \\
\hline UEWP & $-0.011^{* * *}$ & $-0.015^{* * *}$ & $-0.012^{* * *}$ & $-0.007^{* * *}$ & $-0.010^{* * *}$ & $-0.012^{* * *}$ \\
\hline DUM_FRA & $-0.295^{* * *}$ & $-0.454^{* * *}$ & $-0.308^{* * *}$ & 0.027 & 0.017 & 0.023 \\
\hline DUM_IRE & 0.055 & -0.031 & -0.083 & -0.078 & -0.043 & -0.100 \\
\hline DUM_DEN & $-0.357^{* * *}$ & $-0.436^{* * *}$ & $-0.478^{* * *}$ & -0.059 & -0.054 & $-0.157^{* *}$ \\
\hline DUM LUX & -0.113 & $-0.286^{* * *}$ & $-0.301^{* * *}$ & $-0.230^{* *}$ & $-0.229^{* *}$ & $-0.221^{* * *}$ \\
\hline DUM_BEL & $-0.125^{* * *}$ & $-0.176^{* * *}$ & $-0.072^{* * *}$ & 0.008 & 0.000 & $0.040^{*}$ \\
\hline LAMBDA & & & $-1.589^{* * *}$ & & & $-1.574^{* * *}$ \\
\hline Breusch-Pagan test & & $60.624^{\text {*** }}$ & $72.810^{* * *}$ & & $95.820^{* * *}$ & $79.322^{* * *}$ \\
\hline LR-test & & $50.352^{* * *}$ & $138.853^{* * *}$ & & $9.059^{* * *}$ & $94.779^{* * *}$ \\
\hline LM-Error/Lag test & & 2.260 & $16.379^{* * *}$ & & $34.273^{* * *}$ & $69.720^{* * *}$ \\
\hline $\mathrm{AIC}$ & -0.904 & -1.020 & -1.238 & -0.545 & -0.562 & -0.772 \\
\hline No. of Obs. & 416 & & & 416 & & \\
\hline OLS/Spatial & & CRED & & & OTHS & \\
\hline Lag/Error & OLS & Lag & Error & OLS & Lag & Error \\
\hline W_SPEMEU & & $-0.136^{* * *}$ & & & $0.312^{* * *}$ & \\
\hline CONNSTANT & $0.219^{* * *}$ & $0.280^{* * *}$ & $0.242^{* * *}$ & $0.667^{* * *}$ & $0.436^{* * *}$ & $0.648^{* * *}$ \\
\hline CENTR & $0.234^{* * *}$ & $0.224^{* * *}$ & $0.213^{* * *}$ & $0.303^{* * *}$ & $0.330^{* * *}$ & $0.335^{* * *}$ \\
\hline PODEN & $0.250^{* * *}$ & $0.245^{* * *}$ & $0.243^{* * *}$ & 0.000 & -0.006 & 0.003 \\
\hline DIST & 0.000 & 0.015 & 0.017 & $0.000^{* * *}$ & $0.156^{* * *}$ & $0.174^{* * *}$ \\
\hline GRP & $0.001^{* * *}$ & $0.001^{* * * *}$ & $0.001^{* * *}$ & $0.001^{* * *}$ & $0.001^{* * *}$ & $0.001^{* * *}$ \\
\hline QUINN_OPEN & 0.000 & 0.000 & -0.001 & $-0.009^{* * *}$ & $-0.008^{* * *}$ & $-0.009^{* * *}$ \\
\hline AREA & $0.002^{* * *}$ & $0.001^{* * *}$ & $0.003^{* * *}$ & 0.000 & 0.000 & 0.001 \\
\hline UEWP & $-0.006^{* * *}$ & $-0.007^{* * *}$ & $-0.008^{* * *}$ & $-0.003^{* * *}$ & $-0.002^{* *}$ & $-0.003^{* * *}$ \\
\hline DUM FRA & $0.155^{* * *}$ & $0.177^{* * *}$ & $0.145^{* * *}$ & $0.252^{* * *}$ & $0.191^{* * *}$ & $0.251^{* * *}$ \\
\hline DUM_IRE & $0.148^{* * *}$ & $0.188^{* * *}$ & $0.120^{* * *}$ & $-0.603^{* * *}$ & $-0.694^{* * *}$ & $-0.641^{* * *}$ \\
\hline DUM_DEN & $0.181^{* * *}$ & $0.211^{* * *}$ & $0.164^{* * *}$ & $-0.370^{* * *}$ & $-0.442^{* * *}$ & $-0.397^{* * *}$ \\
\hline DUM LUEX & $1.089^{* * *}$ & $1.091^{* * *}$ & $1.008^{* * *}$ & -0.035 & $-0.108^{* *}$ & $-0.182^{* * *}$ \\
\hline DUM BEL & $0.164^{* * *}$ & $0.215^{* * *}$ & $0.182^{* * *}$ & $0.414^{* * *}$ & $0.318^{* * *}$ & $0.442^{* * *}$ \\
\hline LAMBDA & & & $-1.452^{* * *}$ & & & $-0.733^{* *}$ \\
\hline Breusch-Pagan test & & $63.845^{* * *}$ & $75.161^{* * * *}$ & & $49.522^{* * *}$ & $79.063^{* * *}$ \\
\hline LR-test & & $13.641^{* * *}$ & $61.112^{* * *}$ & & $12.914^{* * *}$ & $5.300^{* *}$ \\
\hline LM-Error/Lag test & & $31.808^{* * *}$ & 0.836 & & $38.744^{* * *}$ & $40.698^{* * *}$ \\
\hline $\mathrm{AIC}$ & -2.627 & -2.655 & -2.774 & -1.956 & -1.982 & -1.968 \\
\hline No. of Obs. & 416 & & & 418 & & \\
\hline
\end{tabular}


TABLE A5 (Continued)

\begin{tabular}{|c|c|c|c|}
\hline \multirow{2}{*}{$\begin{array}{l}\text { OLS/Spatial } \\
\text { Lag/Error }\end{array}$} & \multicolumn{3}{|c|}{ NMSE } \\
\hline & OLS & Lag & Error \\
\hline W_SPEMEU & & $-0.698^{* * *}$ & \\
\hline CONSTANT & $0.775^{* * *}$ & $1.592^{* * *}$ & $0.604^{* * *}$ \\
\hline CENTR & $0.781^{* * *}$ & $0.731^{* * *}$ & $0.706^{* * *}$ \\
\hline PODEN & $-0.085^{* * *}$ & $-0.077^{* * *}$ & $-0.061^{* * *}$ \\
\hline DIST & $0.000^{* * *}$ & $0.158^{* * *}$ & $0.249^{* * *}$ \\
\hline GRP & $-0.003^{* * *}$ & $-0.003^{* * *}$ & $-0.003^{* * *}$ \\
\hline QUINN_OPEN & $0.021^{* * *}$ & $0.024^{* * *}$ & $0.022^{* * *}$ \\
\hline AREA & 0.000 & 0.000 & -0.001 \\
\hline UEWP & $0.020^{* * *}$ & $0.027^{* * *}$ & $0.023^{* * *}$ \\
\hline DUM_FRA & 0.033 & $0.077^{* * *}$ & 0.040 \\
\hline DUM_IRE & $-0.414^{* * *}$ & $-0.353^{* * *}$ & $-0.272^{* * *}$ \\
\hline DUM_DEN & $0.334^{* * *}$ & $0.432^{* * *}$ & $0.434^{* * *}$ \\
\hline DUM_LUX & $-0.903^{* * *}$ & $-0.371^{* * *}$ & $-1.281^{* * *}$ \\
\hline DUM_BEL & $0.377^{* * *}$ & $0.501^{* * *}$ & $0.403^{* * *}$ \\
\hline LAMBDA & & & $0.945^{* * *}$ \\
\hline Breusch-Pagan test & & $201.816^{* * *}$ & $111.626^{* \% *}$ \\
\hline LR-test & & $54.358^{* * *}$ & $65.563^{* * *}$ \\
\hline LM-Error/Lag test & & $122.005^{* * *}$ & $66.555^{* * *}$ \\
\hline AIC & -0.761 & -0.884 & -0.915 \\
\hline No. of Obs. & 425 & & \\
\hline
\end{tabular}

